Bull. Fac. Agric., Cairo Univ., 71: 1-14 (2020).

\title{
INDICATIVE NEEDS OF THE FARMER WITH REGARD TO THE TECHNICAL RECOMMENDATIONS FOR THE INTEGRATED CONTROL OF THE ROTARY MOLD LESION AFFECTING THE MANGO CROP IN ISMAILIA GOVERNORATE, EGYPT
}

(Received: 24.2.2020)

\author{
By \\ A. A.Sh A.Al- Qarqari and Shaimaa E.M. El Sbayee \\ Agricultural Extension and Rural Development Research Institute (AERDRI) \\ Agricultural Research Center, Giza, Egypt
}

\begin{abstract}
The main aim of the present research was to determine the level of knowledge and operational requirements of the farmers concerned in relation to the technical recommendations for the control of rotary mold pests in Ismailia Governorate, and to determine the nature of the relationship between the farmer's level of the total knowledge and operational requirements with these technical recommendations. And, to identify the sources of information from which the farmers obtained their agricultural information on the control of these pests in Ismailia Governorate, in addition to identify with the most important agricultural extension activities provided to the farmers by the agricultural extension system for farmers in this regard. The research was conducted in Ismailia on a random random sample of 256 respondents as $34 \%$ of the total size of 750 farmers, using the equation of Krisgei and Coral, and collected research data using a questionnaire designed for purpose. A preliminary test of the questionnaire was conducted by interviewing 30 respondents from the village of Toson in the Ismailia Center to verify the accuracy of the form. The appropriate modifications were made in the form and became valid for collecting the data. The data were collected in a month during the period from 30.3.2019 -30.4.2019. For the statistical analysis, the following statistical tools were used: the frequencies, the arithmetic averages and the percentages. The results showed that the levels of knowledge and total operational requirements regarding the technical recommendations for the integrated control of the mold pest were $81.6 \%$ and $83.6 \%$ of the surveyed farmers, respectively.

The total knowledge and operational requirements of the surveyed farmers with respect to the technical recommendations for control of crustacean were of the causes of the mango bean mold lesion with high mango yield of $80.4 \%, 81.1 \%$ of the surveyed farmers and the total knowledge. And, operational needs of the farmers concerned with respect to the technical recommendations for control of the insecticide, were of the causes of the mold pest of the mango crop and were higher for the two levels at $83.2 \%$ and $84.4 \%$ of the surveyed farmers. The levels of total knowledge and operational requirements of the technical recommendations for insecticide control for deforming were of the causes of the mildew mold lesion in the research area $(78.5 \%$ and $78.2 \%$, respectively. And, that the levels of total knowledge and operational requirements of the investigated farmers in relation to the technical recommendations for pesticide control for a range of other fungal diseases were of the causes of the moldy mold lesion in the research area was high for both levels by $65.2 \%$ and $65.2 \%$, respectively. And the general level of the total knowledge and operational needs of the farmers concerned with the technical recommendations for the integrated control of the mold pest in the research area was $77.7 \%$ and $78.6 \%$ respectively. And the most important sources from which the farmers derive their information about integrated control of agricultural pests affecting the mango crop In the research area are: Relatives, friends, neighbors, pesticide dealers have pest information and control, radio and television programs provide us with expert information about symptoms and pest control, and local leaders provide us with all that is new about the lesion bin B ranged from $65.3 \%$ to $84.4 \%$, and the most important extension services provided by agricultural extension from their point of view to deal with the agricultural risks caused by the mold pest in the research area are: visits by the guide to the field and the houses of farmers, and visit by the farmers to the Office of Agricultural Extensioners for discussions between farmers and guides to seek guidance and advice on ways to
\end{abstract}


deal with the source of mold rotary to reduce the risk to the crop. And the holding seminars and meetings and set up field guidance for the farmers to acquire new knowledge in the field of control of the rotten mold in the search area rates ranged between $14.5 \%$ to $40.2 \%$.

Key words: indicative needs, mango crop, rotary mold lesion, ismailia governorate.

\title{
الاحتياجات الإرشادية للزراع فيما يتعلق بالتوصيات الفنية الخاصة بالمكافحة المتكاملة لآفات العفن الهبابي

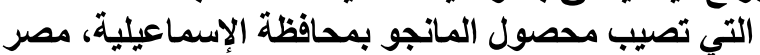

\author{
أبومسلم علي شحاته ابوزيد القرقاري - شيماء السيد محمد السباعى \\ معهد بحوث الارشاد الزراعي والتنمبية الريفية - مركز البحوث الزراعيةـ الجيزة ـ مصر
}

\begin{abstract}
ملخص

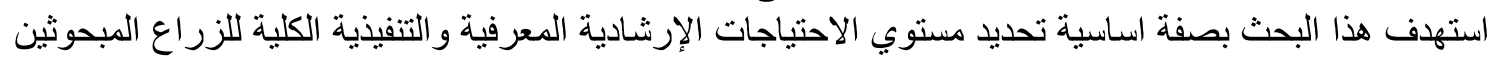

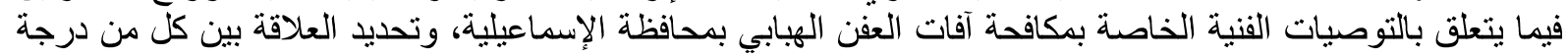

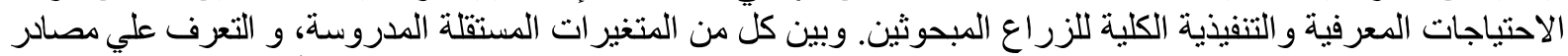

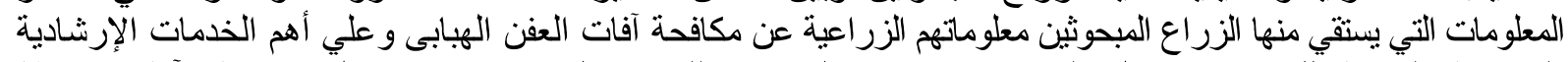

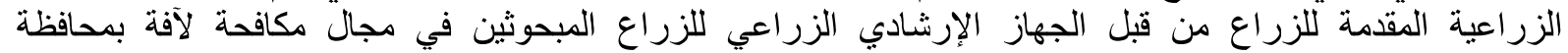

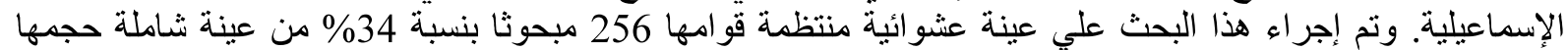

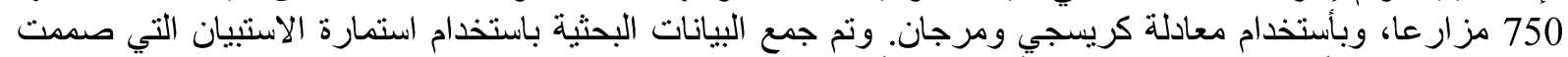

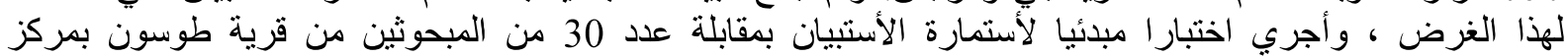

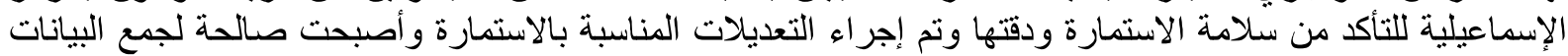

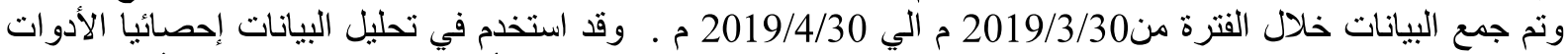

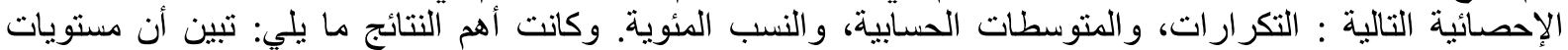

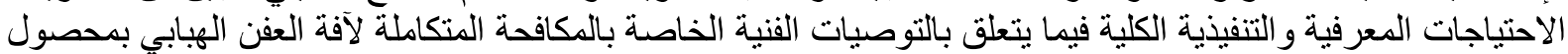

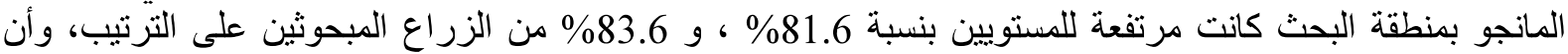

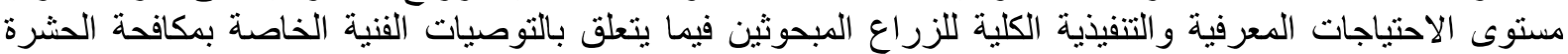

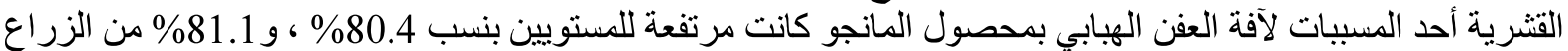

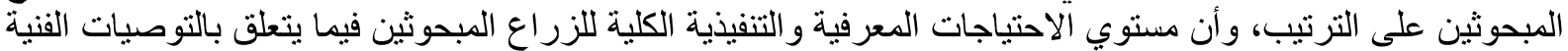

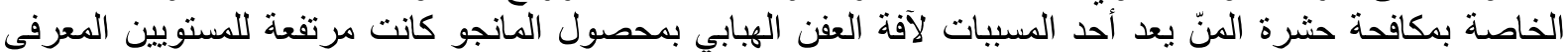

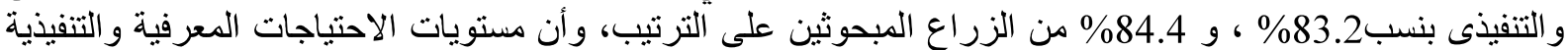

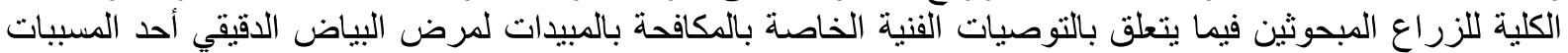

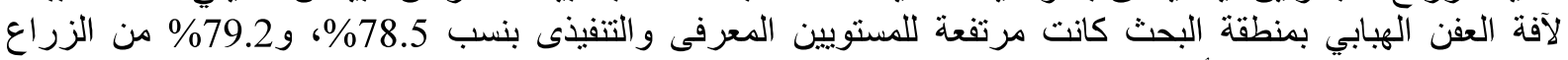

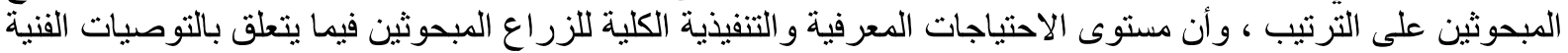

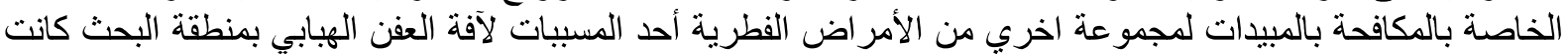

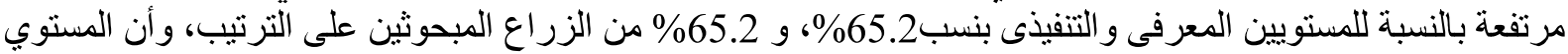

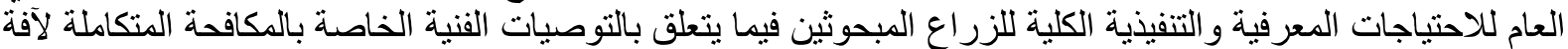

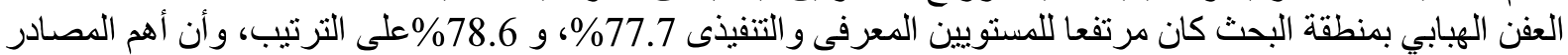

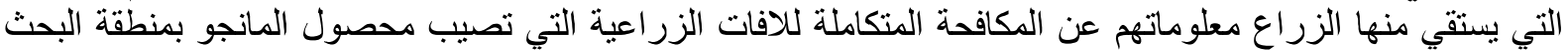

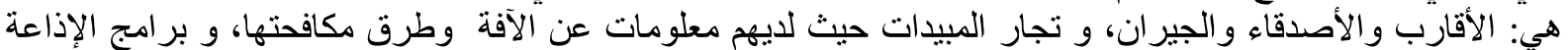

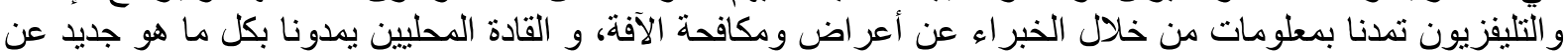

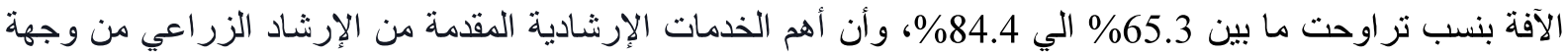

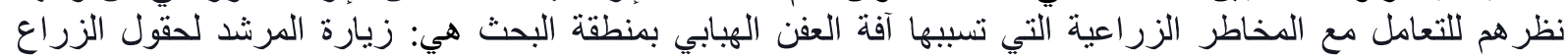

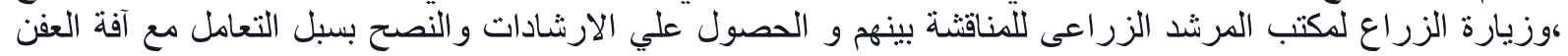

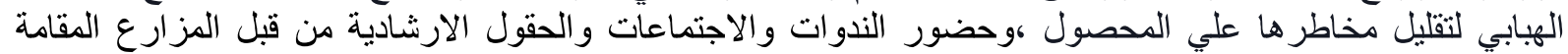

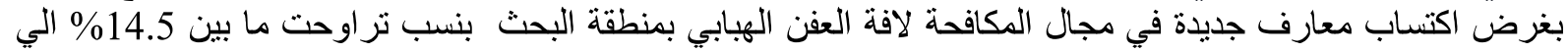

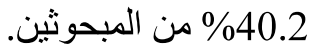


مما يؤدي الي تجمع مزيدا من الحشر ات و الأمر اض الأكثر

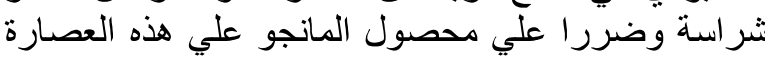

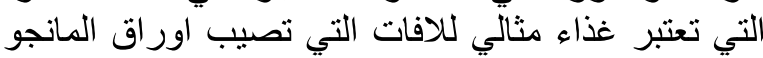

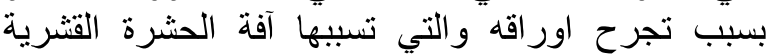
وغير ها من الآفات المسبية للعفن الهبابي.

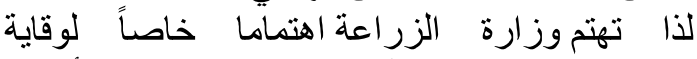

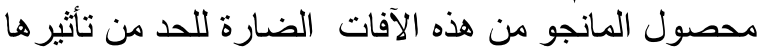

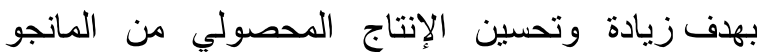

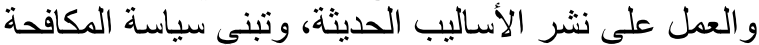

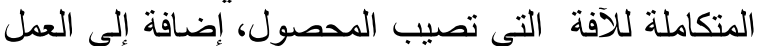

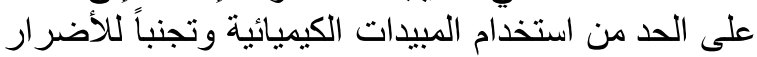

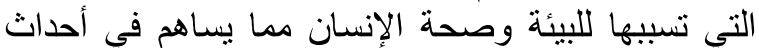

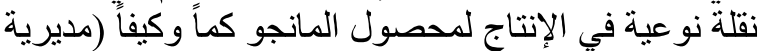

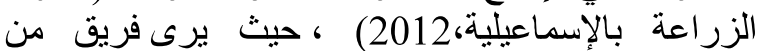

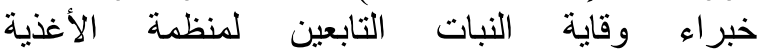

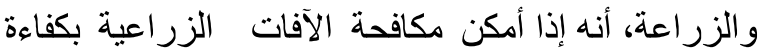

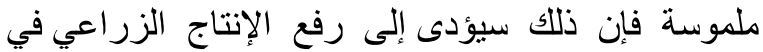

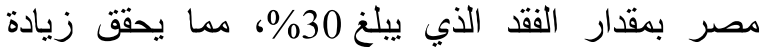
إجمالية في الناتج الزر اعي القومي قدره 30 مليون طن من الأن

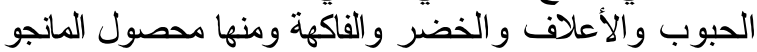

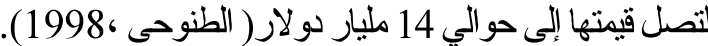

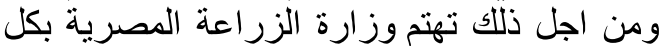

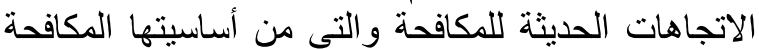

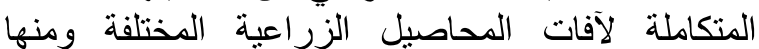
محصول المانجو بما يحقق الإدارة المتكاملة لإعلة لمكافحة

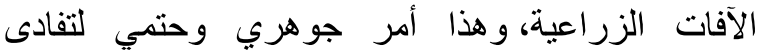

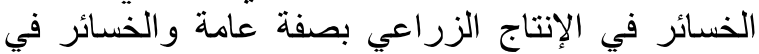

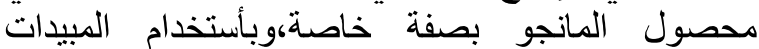

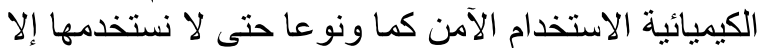

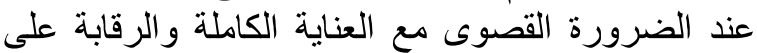

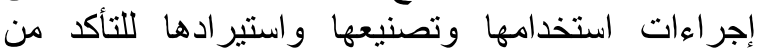
صلاحيتها للاستخدام ومطابقتها للمواصفات وتئهات والقيات القاسات

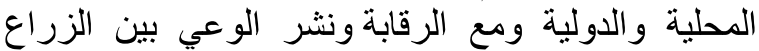

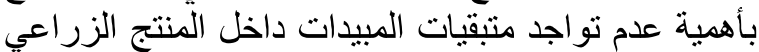

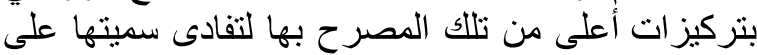
الإنسان و الحيوان، وتفادي رفضئها في العي الأسواق المحلية

و العالمية، (دبور وشاكر ، 1982).

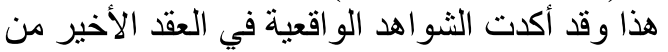

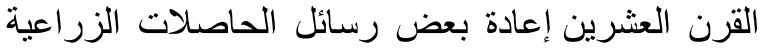

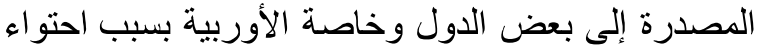

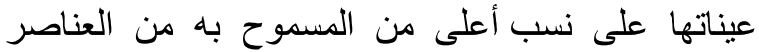

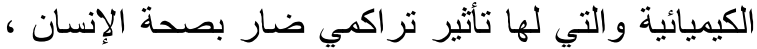
وذللك نتيجة الإفراط في التئية التخدام الأسمدة الكيميائية والمغالاة في استخدام المبيدات الكيميائية لركافحة الآفات الزيات

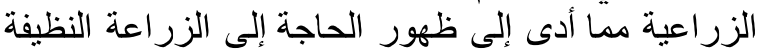

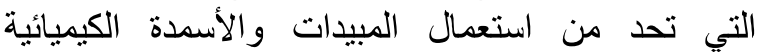
والأستناد بصفة رئيسية إلى المكافحة المتكاملة واستعمال الأسمدة العضوية و الحيوية

( Blackman and Eastop 1984)
تعد الآفات الزراعية التي تصيب التيب الحاصلات

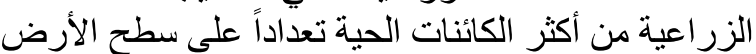

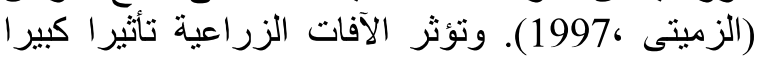

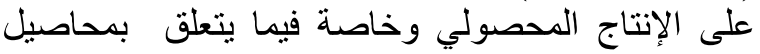

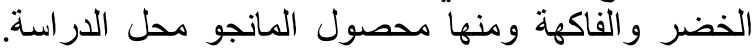

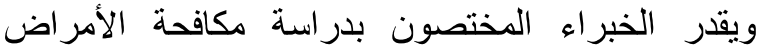
والحشرات التي تصيب الحاصلات الزراعية في منظمة التئة الفاو بالأمم المتحدة ان نسبة الفقد التي تسببها الآفات التيات

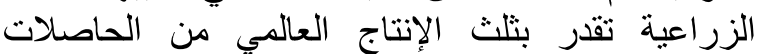

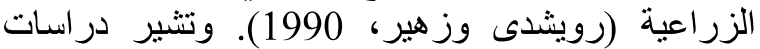

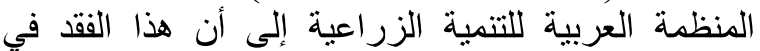

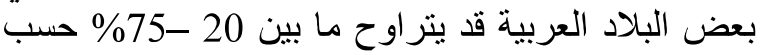

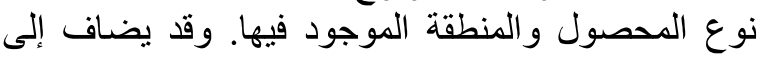
الخسائر بسبب الآفات الزراعية حوالي 10-20\% من وتئ

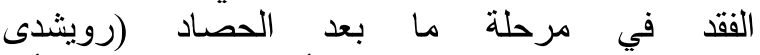

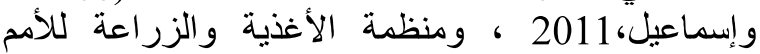

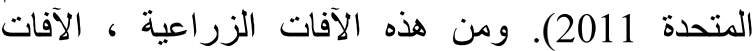

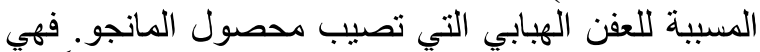

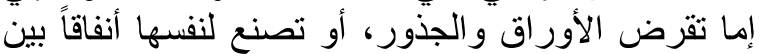

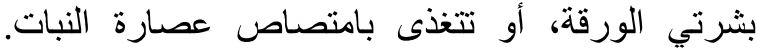

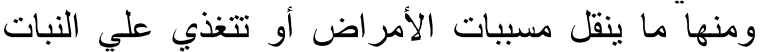

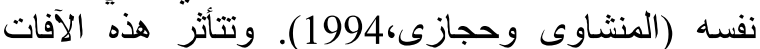

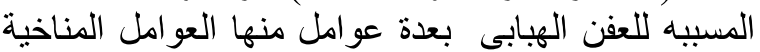

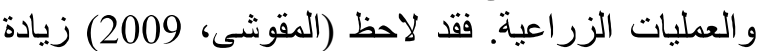

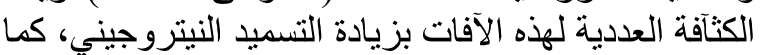

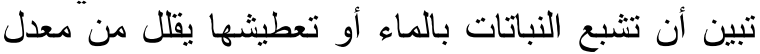

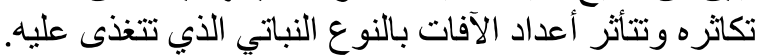

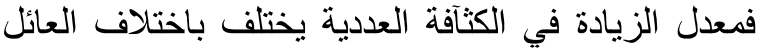

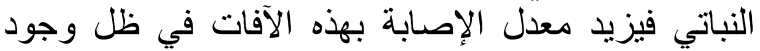
اشجار عائلة الحلويات والاشجار ذاية ذات النات النواة الحجرية

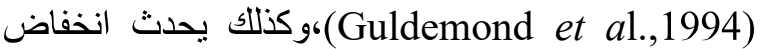

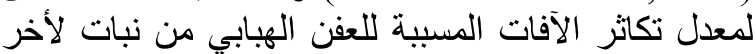

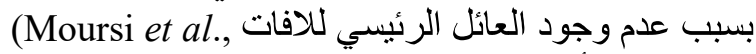

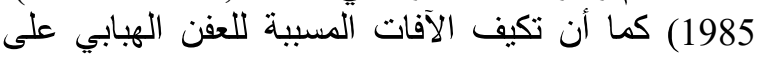

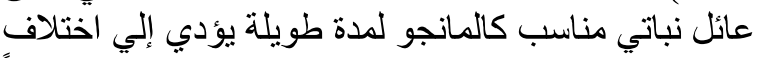

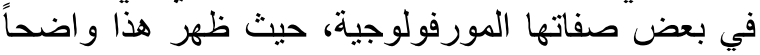

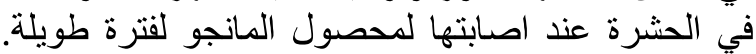
ولقد ذهب بعضهم إلى تعريفها كنوع جديد من الافات الزر اعية (Alahmadi and Salem,1999). وتعتبر الآفات المسبية للعفن الهبابي أحد العوامل

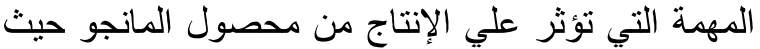

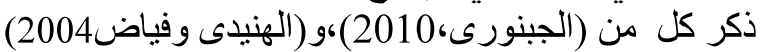

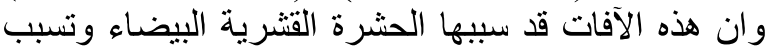

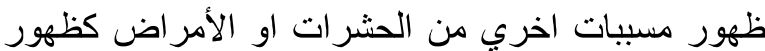

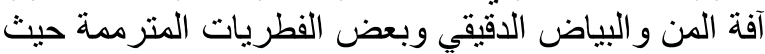
تسبب هذه الآفات في تجرح الئي اوراق المانجو العليا وحدوث

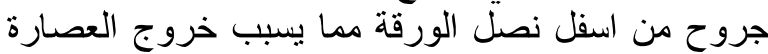
النباتية اللزجة ونزولها علي السطح العلوي للاوراق السفلي 
علميا لاستخلاص المادة الارثشادية ثم وصفها فى برامج

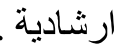

\section{2.مشكلة البحث}

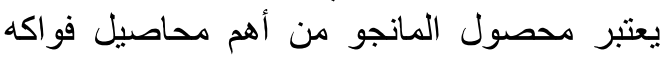

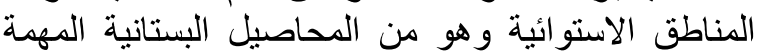
بمصر وتعتبر محافظة الإسماعيلية أهم الهم محافظات الهاتية

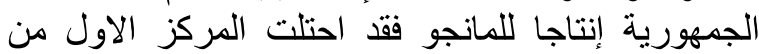
حيث المساحة والإنتاج فتبلغ إير ادات محافظة الإسماعيلية الإنية

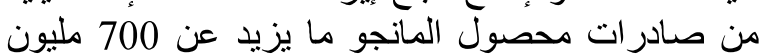
دولار ومن الأسواق المحلية حوالي 200 مليون دوليار

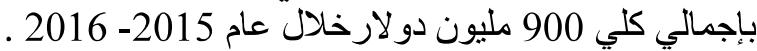
وكان من المأمول زيادة هذه الاير ادت إلادي إلي ما يزيد عن عن

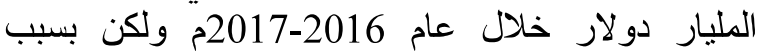

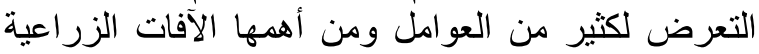

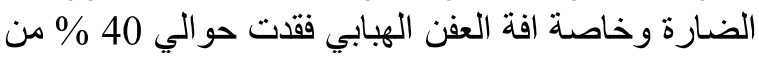

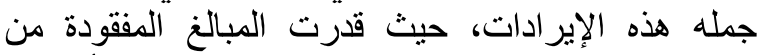

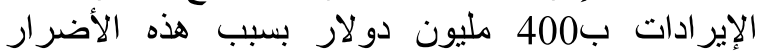
السابق ذكرها. ولا يوجد ادني شكك في أنه بتوفير فيض الإن الإن

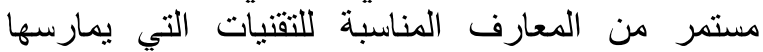

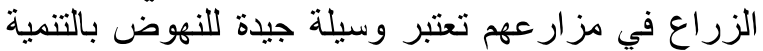

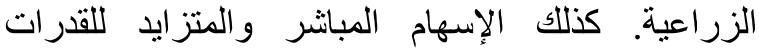

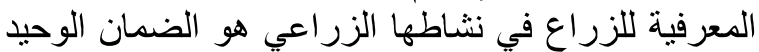

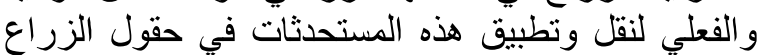

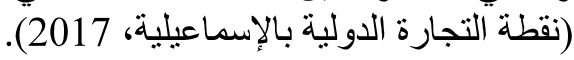
وقد بلغت المساحة المنزر عة من محصول الإعلة المانجو في عام 2007 م 119 الف فدان على مستوى الجمهورية وبمتوسط انتاجية 4.5 طن للفدان ، بينما كانت المساحة الفية الفية

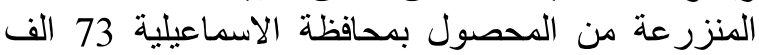
فدان بنسبة 61.3\% من المساحة علي مستوي الجمهورية

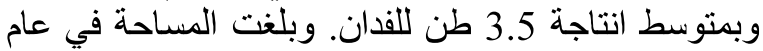

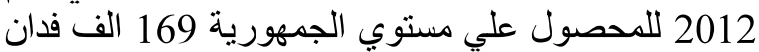
وبمتوسط انتاجية 4 طن للفدان، في حين كانت المساحة

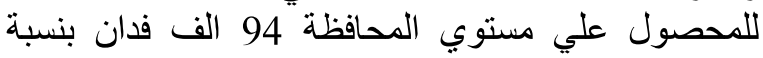

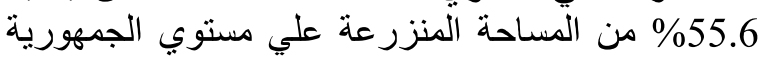

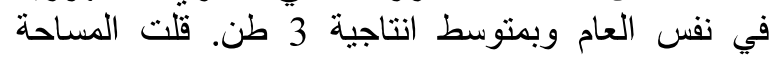
المنزرعة علي مستوي الجمهورية في عام

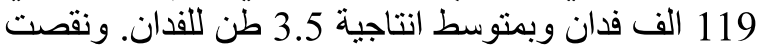

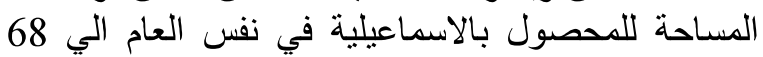

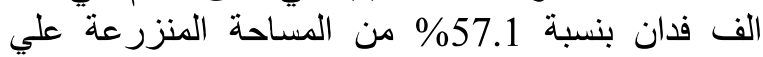
مستوي الجمهورية وبمنوسط انتاجية 3طن للفدان (مديرية الزر اعة بالإسماعيلية ،2017).

ومما سبق يتضح ان هنائك تذبذب في المساحات

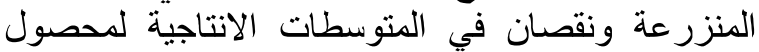

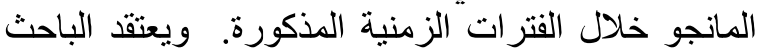

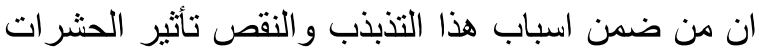

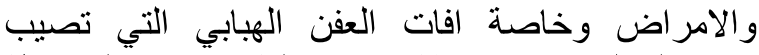

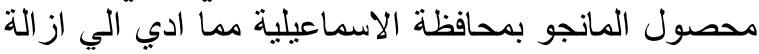

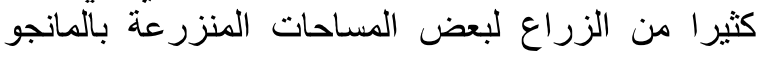

واهتمت الدولة في الآونة الأخيرة بتصميم برامج

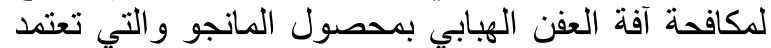
على طرق مختلفة للمكافحة وكان خيار ها الأخير أستخدام المبيدات الحشرية بل تعتمد على استخدام بدائل المبيدات

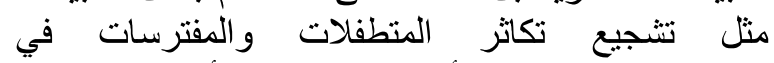

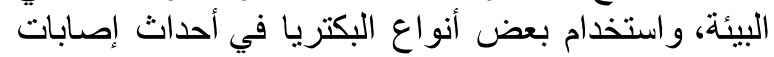

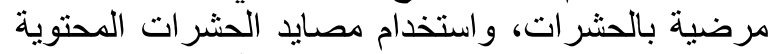

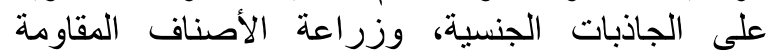

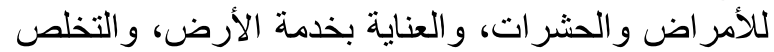

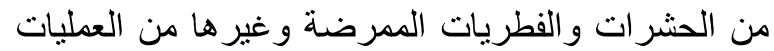

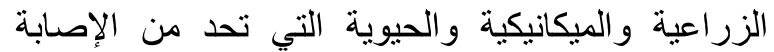

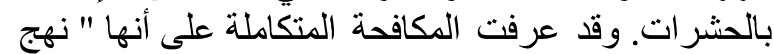

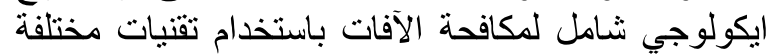
متواصلة في النظام للسيطرة على الآفات (منظمة الأغذية الأنية

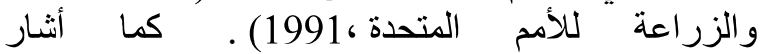

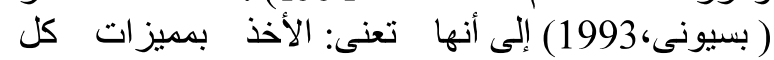

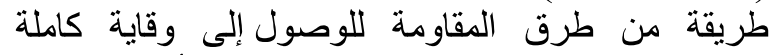

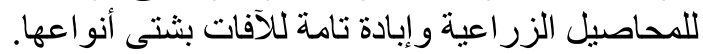

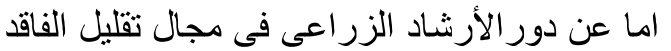

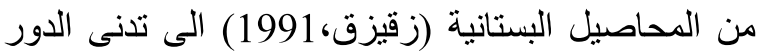

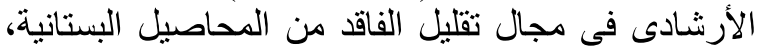

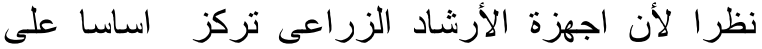

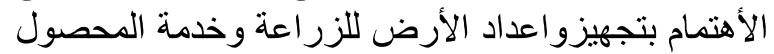

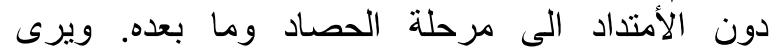
شاكر(2001) ان الأرشاد الزراعى يمكن ان يلعب دوراد الزيا

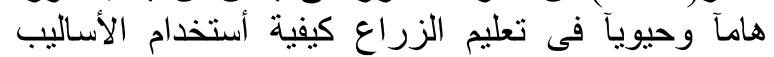
الزراعية الحديثة من خلال العملية التعليمية التى يقوم بهات الأيا

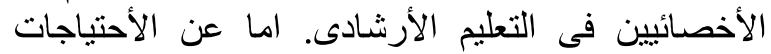

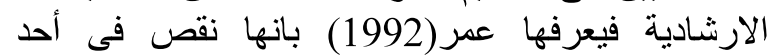

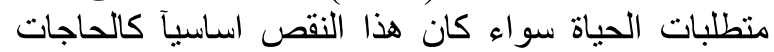

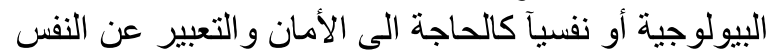

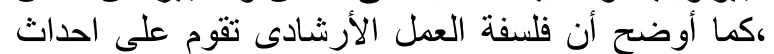

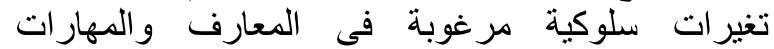
والأتجاهات لجمهور المسترشديين وذلك لبناء لبناء حياة أفضل

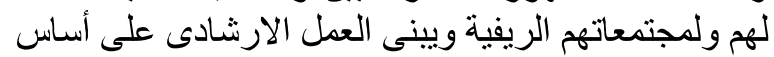

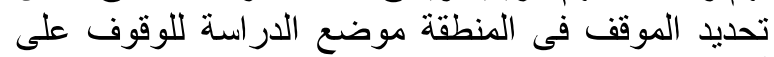

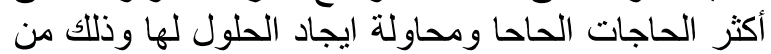

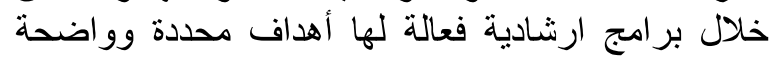

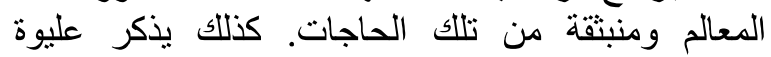

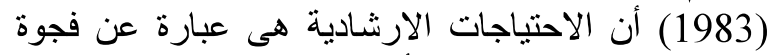

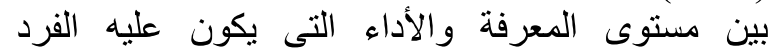

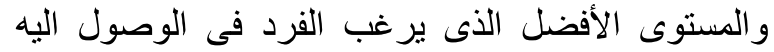

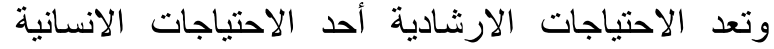

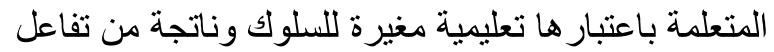

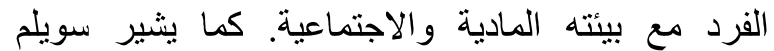

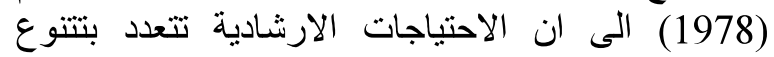

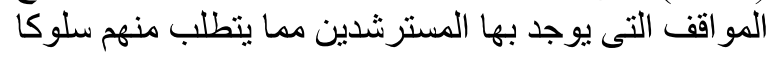

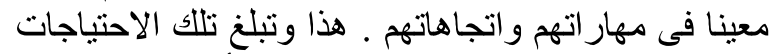

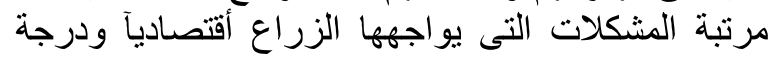
حساسيتهم بها واتجاهاتهم بالنسبة لها ومن ثم دراستها 
4-تحديد العلاقة بين كل من مستوي الاحتياجات التنفيذية الكلية للزراع المبحوثين فيما يتعلق بالتوصيات الفينية الفينة

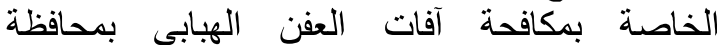
الإسماعيلية وبين كل من المتغيرات المئية المستقلة المدروسة السابق ذكر ها.

5- التعرف علي مصادر المعلومات التي يستقي منها الزراع الزئي

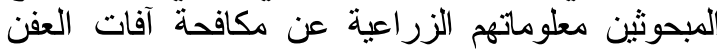
6 الهبابى بمحافظة الإسماعيلية. 6- التعرف علي أهم الخدمات الإرشادية الزراعية الإية المقدمة

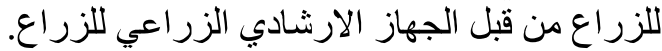

\section{الفروض البحثية}

تحقيقا لأهداف البحث الثانى والرابع تم وضع الفروض البحثية التالية : البافية

1-نوجد علاقةًة معنوية بين درجة الاحتياحات المعرفية

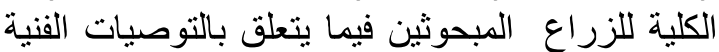

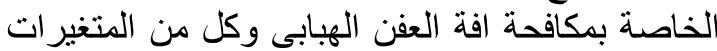

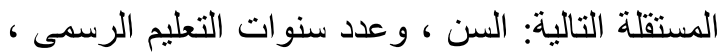

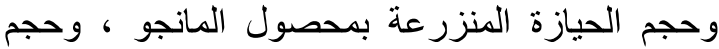

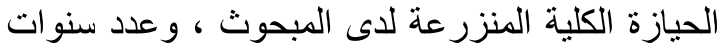

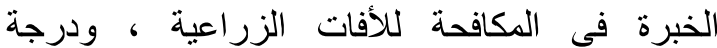
المشاركة المجتمعية الرسمية ، وليكة ودرجة الزية المشاركة

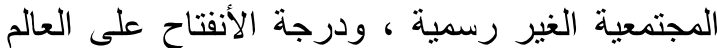
الخارجى ، ودرجة القيادية الغيلة ودئ

2- توجد علاقة معنوية بين درجة الاحتياجات التنفيذية

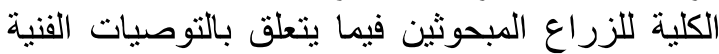

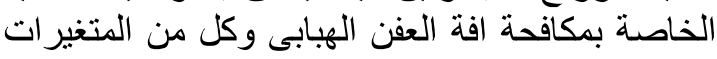
المستقلة المدروسة السابق ذكر ها.

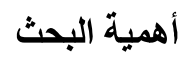

تبرز أهمية هذا البحث من خلال النتائج المتوقع

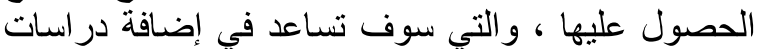

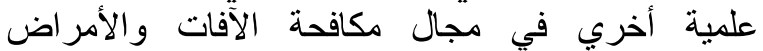
الزراعية الضارة بالإنتاج الزر اعي وحتى يتمكن الباحثين

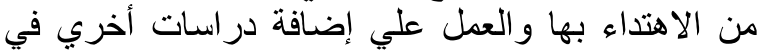

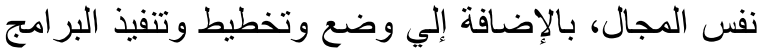

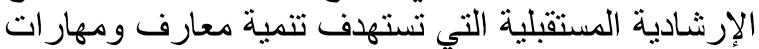

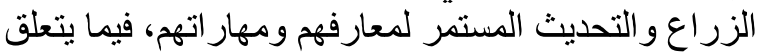

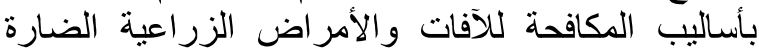

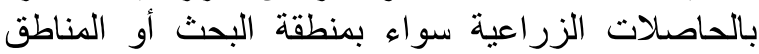

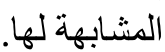

التعريفات إلأجرائية

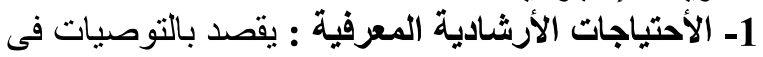

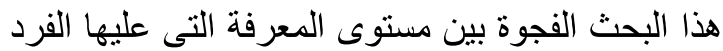
فيما يتعلق بالتوصيات الفنية الخاصة بلتئ بالمكافحة

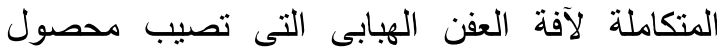

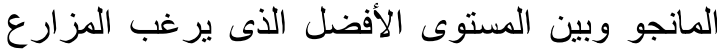

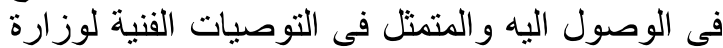

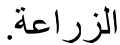

2- الأحتياجات الرشادية التنفيذية: يقصد بها فى هذا البحث نواحى النقص لدى زراع المادية: المانجو من حيث في
بالدحافظة وهذا ما جعل هنالك ضرورة لأجراء هذا

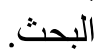

لذلك فأن مكافحة آفة العفن التي تصيب محصول

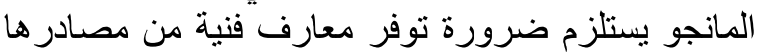

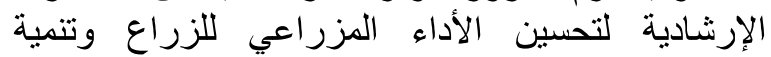

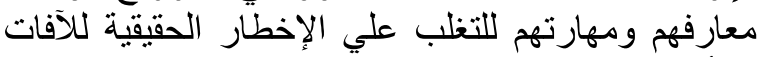

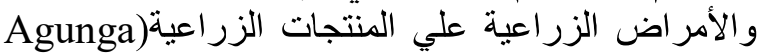

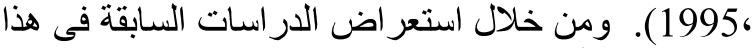

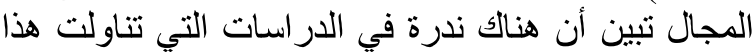

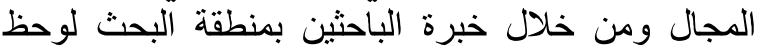

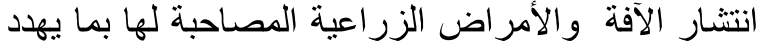

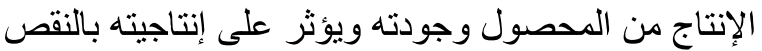

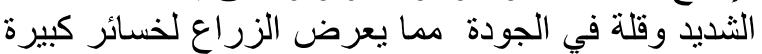

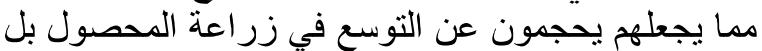

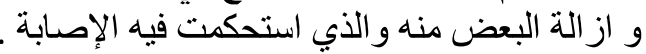
لذلك تم إجر اء هذا البحث للتعرف علي التي الاحتياجات

الإرشادية المعرفية والتنفيذية للزراع التهاع في مجال مكافحة الاحتية الآفات التي تصيب محصول المانجو بمحافظة الإسماعيلية و لمحاولة الأجابة علي التساؤلات التالية:

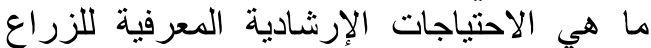

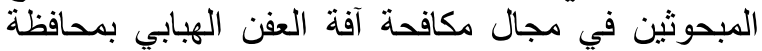

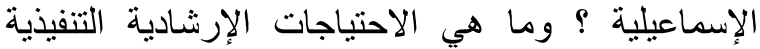

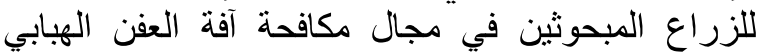

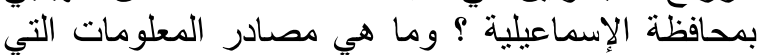

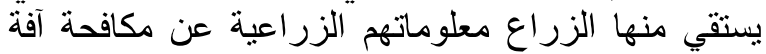

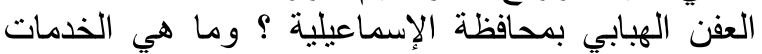

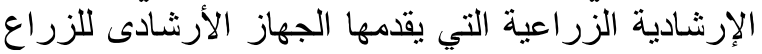
فى مجال مكافحة آفة العفن الهبابي بمحافظة الإسماعيلية ؟

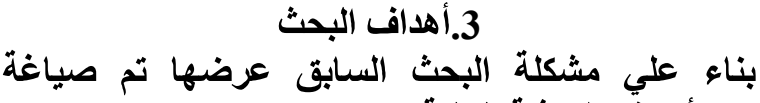
الأهداف البحثية التالية:-

1- تحديد مستوي الاحتياجات الإرشادية المعرفية الكلية للزراع المبحوثين فيما بتعلق بالتوصيات الإنيات الفنية الخاصية بمكافحة آفات العفن الهبابي بمحافظة الإسماعيلية بلئية 2- تحديد العلاقة بين كل من درجة الاحتياجات الإنيات المعرفية الكلية

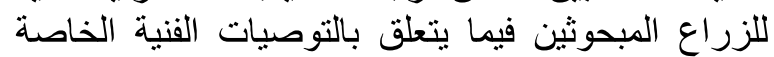

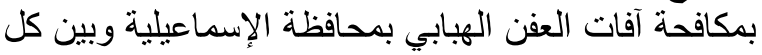

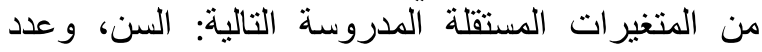

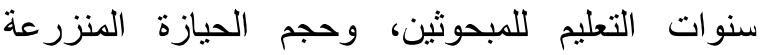

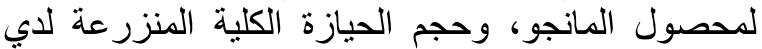

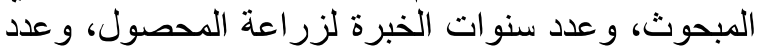

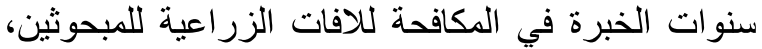

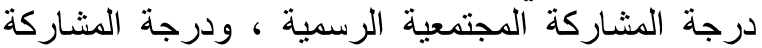

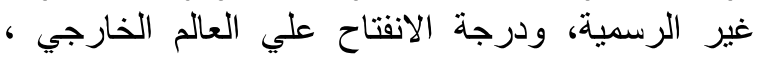
ودرجة القيادية للمبحوثين. 3- تحديد درجة الاحتياجات الإرشادية التنفيذية الكلية للزراع باعية

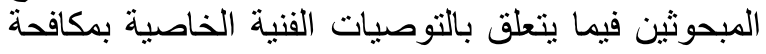
آفات العفن الهبابي بمحافظة الإسماعيلية. 
4- حجم الحيازة المنزر عة بمحصول المانجو تم قياسها من لأن خلال عدد الأفدنة لاى المبر المبحوثين.

5-اجمالي الحيازة المنزرعة تمثيدة قياسهها من خلال عدد الأفدنة لدي المبحوثين.

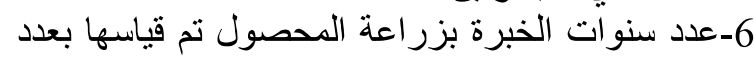
سنوات الخبرة الفعلية للمبحوث بزاعة الفراعة محصول

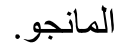

7-عدد سنوات الخبرة في مكافحة الافات الزر اعية بعدد سنوات الخبرة الفعلية للمبحوث في مكافحة الأفات التى التى التى التئ تصيب محصول المانجو. 8-المشاركة المجنمعية الرسمية نم قياسها من خلال منح

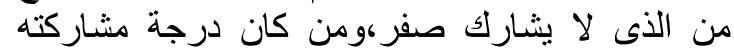

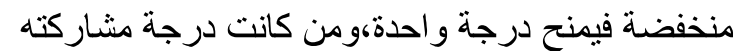

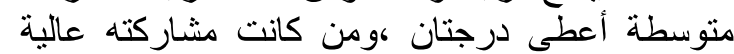

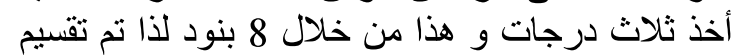
هذا المتغير الى ثلاث درجات مستويات هى درل درجة مشاركة

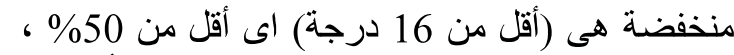

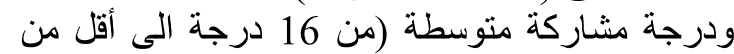

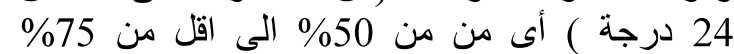
كودرجة مشاركة عالية (من 24 درجة فأكنة الكثر ) أى 075\% 6أكثر.

9-المشاركة المجتمعية غير الرسمية : تم قياسها من خلال

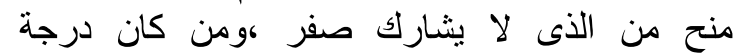

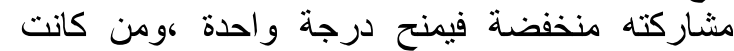

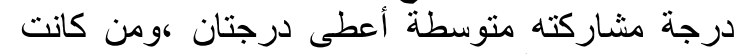

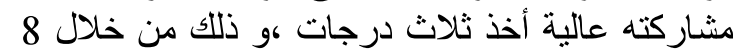

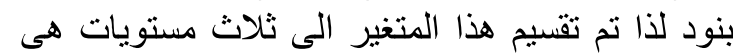

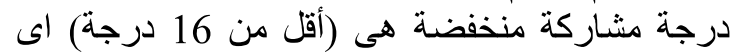

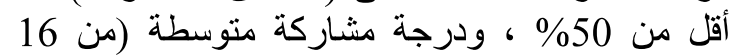

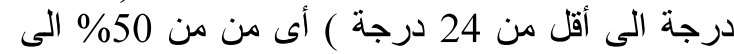
اقل من 75\% ،ودرجة الى من مثاركة عالية (من24 درجة درجة

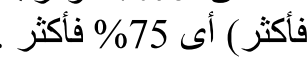

درجة الانفتاح علي العالم الخارجي: نم قياسها من خلال

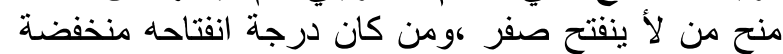

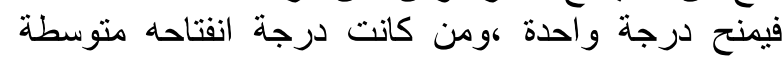

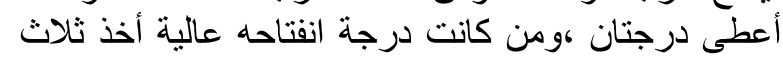

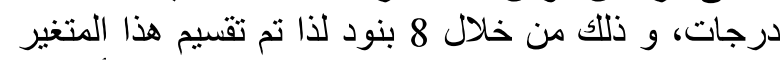

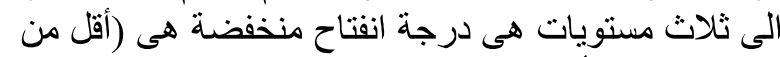

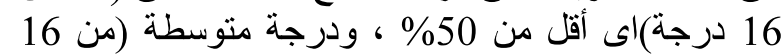

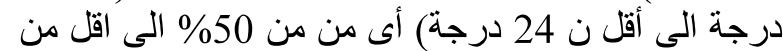
75\% ،ودرجة انفتاح عالية (من24 درجة درجة فأكثر) أى 75 الى

درجة القيادية للمبحوث فتم قياسهر من خلال منح الذي ليس له ميول قيادية صفر، ومن ومن كان درجة درنة قيادته

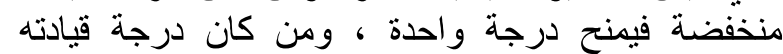

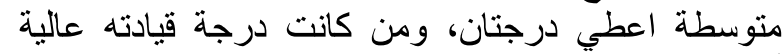

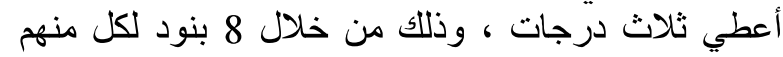

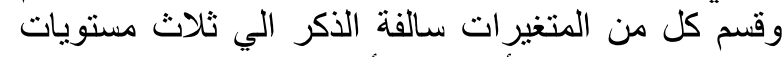

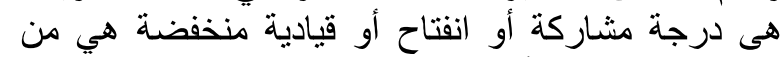
(اقل من 16 درجة أو اقل من 50\%) ودرجة أنغاحة متوسطة (من
المعلومات والمهارات التنفيذية المتعلقة الفية الخاصة بالمكافحة المتكاملة لأفة العفن الهبابى.

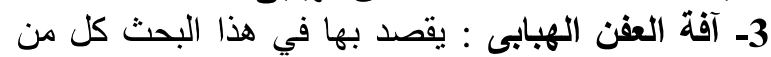

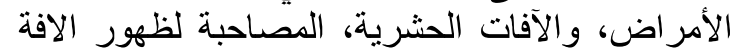

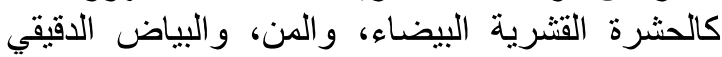

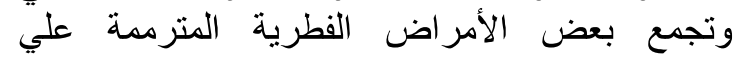
الإفرازات الناتجة عن الجروح التي سبيتها الحشرات التئي

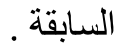

\section{4.الطريقة البحثية} منطقة البحث وعينته

تم إجراء هذا البحث بمحافظة الإسماعيلية لما تتميز

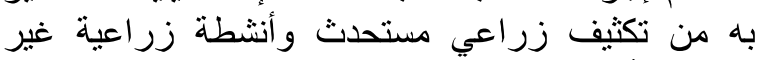
تقليدية الأمر الذي يؤدي إلي تعدد وتنوع وانتئنار الآناتيات

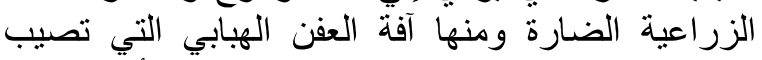

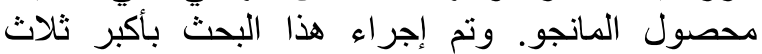

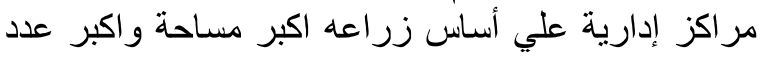

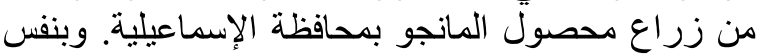

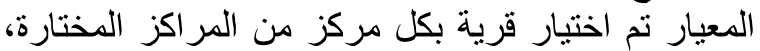

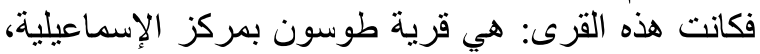

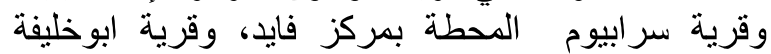
بمركز القنطرة غرب، وتم اختيار العينة بطريقة عشوية ائية ائية منتظمة من كثوف الحصر العدري بردي بالجمعيات الزراعية بهذه القري وعددهم 750 مزارعا، وبأستخدام معادلة العيدية

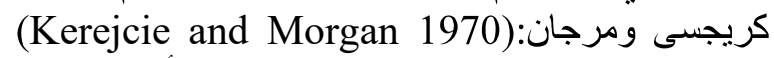
بلغ حجم العينية 256 مبحوثا بنسبة 34\% من من أجمالي حجم

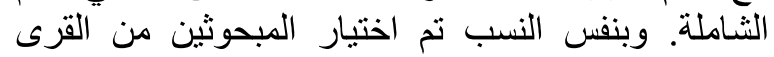

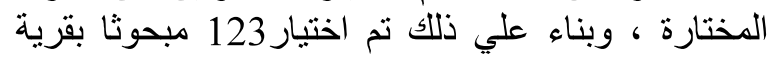

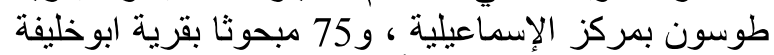

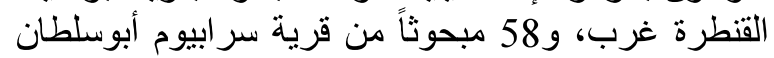

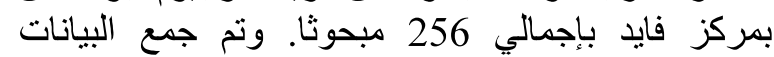
بالدقابلة الشخصية باستخدام استمارة الاستبيان التئي التياني

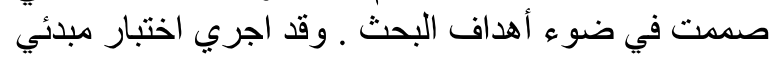

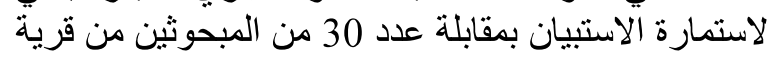
طوسون بمركز الإسماعيلية للتأكد من سلامة الإنيلة الاستمارة

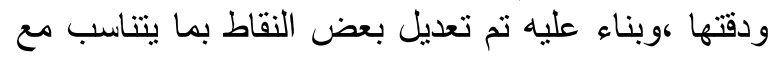

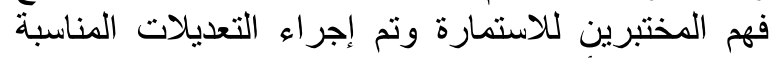

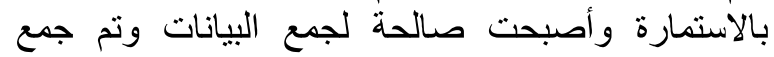

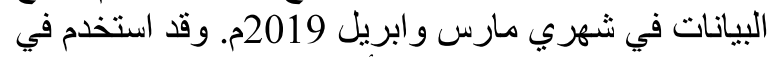
تحليل البيانات إحصائيا الأدوات الإحصائيلية التالية:

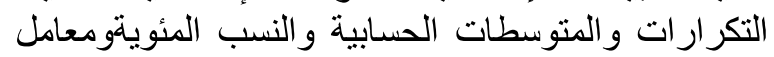

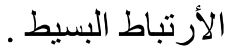

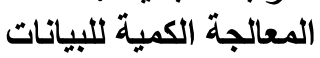

تم معالجة البيانات المتحصل عليات عليها من استجابات

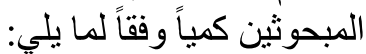
اولا: قياس المتغير التئ المستيتلة

1- تم قياس المتغير الميرات المستقلة للعينة المدروسة، حيثة حيث تم

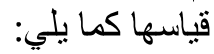

2- السن بعدد سنوات عمر المبحوث. 3- عدد سنوات التعليم الرسمى بعدد سنوات التبح التعليم الفعلية . 
بآفة المن العسلي أحد الآفات المسبية لآفة العفن الهبابي

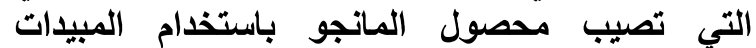
بمحافظة الإسماعيلية: بلغ عدد توصياتها الفنية 8 توصيات ولجية وعلى ذلك تراوحت

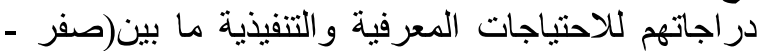

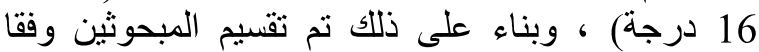

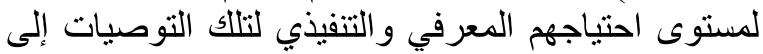
ثلاث فئات هي: درجة احتياج معرفي وتنفيذي منخفض لتون

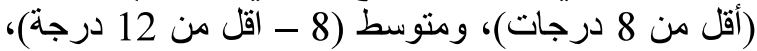
ومرتفع ( 12 درجة فأكثر) .

4- حزمة التوصيات الخاصة بالاحتياجات المعرفية

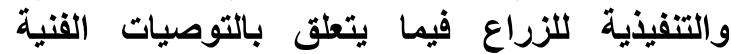
الخاصة بآفة البياض الاقيقي أحد الآفات المسببة لآئة

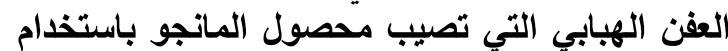
المبيدات بمنطقة البحث :

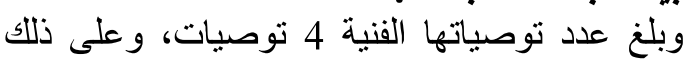

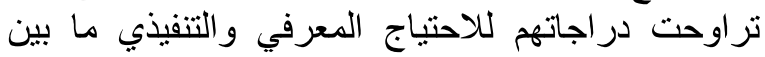
(صفر - 8 درجات) ، وربناء على ذلكاتك تم تقسيم ألمبحوثين

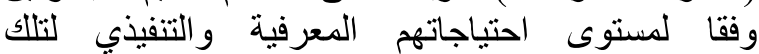

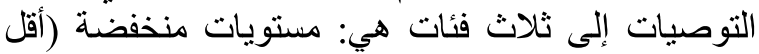

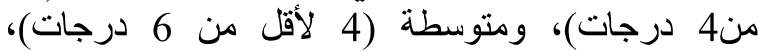

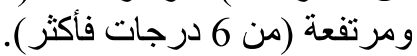

5- حزم التوصيات الفنية الخاصة بالاحتياجات المعرفية

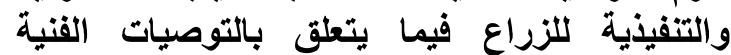
الخاصية بالأمراض الفزراعة فيمة المترممة أحد الآقات الفية

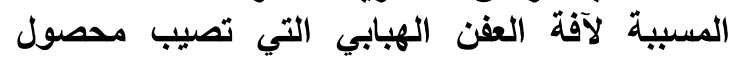
المانجو باستخدام المبيدات بمحافظةً الإسماعيلية

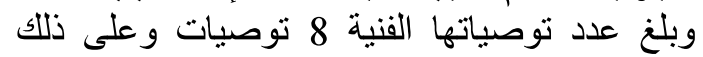

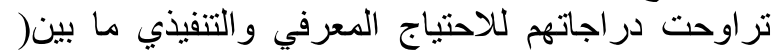

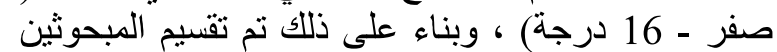

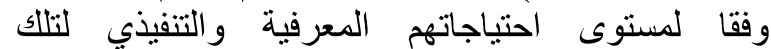

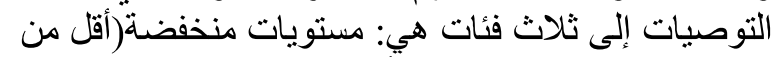
8 درجات)، ومتوسطة (8 لأقلّل من 12 درجة)، ومرتفعة (12 درجة فأكثر ).

ثالتا: للتعرف علي كل من مصادر المعلومات التي يستقي منها

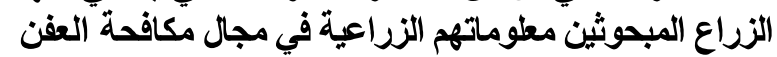
الهبابي بمحافظة الإسماعيلية، وقعلي الرئي أهم الأنشطة

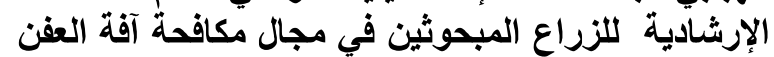

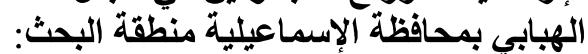

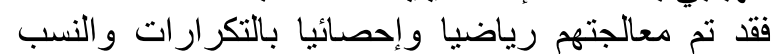
المئوية.

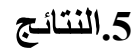

$$
\text { اولا: وصفين عن النتائجة ما يلي: }
$$

اظهرت النتائج الواردة بالجدول (1) بان 50\%من أفراد

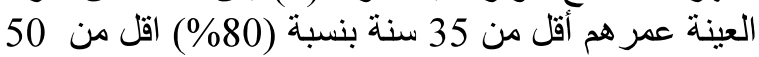
سنة ، و بلغ نسبة من بلغ 50 سنة فأكثر 10.2 \% \%
16 درجة لأقل من 24 درجة او من 50 \% \% الي اقل من

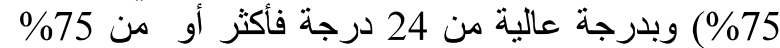

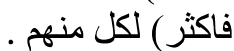

ثانيا: قياس المتغير لثنات التابعة

تم قياس درجة الأحتياجات الأرشادية المعرفية

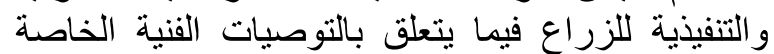

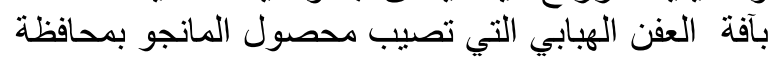

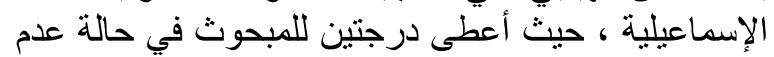

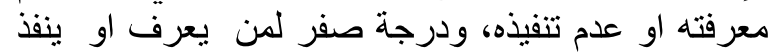

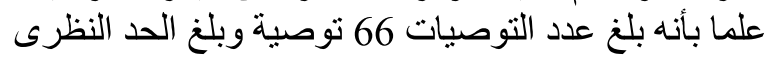

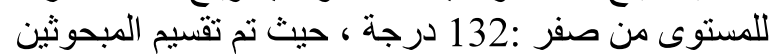
وفقآ لدرجة أحتياجاتهم المعرفية والتنفيذية الى ثثلاث فئات

$$
\text { 1 وهى : رجة احتياج معرفى وتنفيذى منخفض (من صفر الى الى }
$$

66 درجة) .

2- درجة احتياج معرفى وتنفيذى متوسط (من 66 درجة

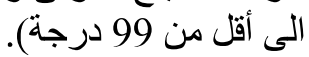

3- درجة احتياج معرفى وتنفيذى مرتفع (من 99 درجة فأكثر ).

*وقد قدر عدد حزم التوصيات الفنية التي تم در استها 5 حزم موز عة بالدرجات كمة كما يلئ: 1- حزمة التوصيات الخاصة بالاحتياجات المعرفية والتنفيذية باتية للزراع فيما يتعلق بالتوصيات الفنية الخاصة باتلة بالمكافحة

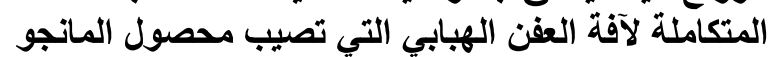

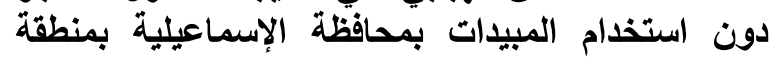

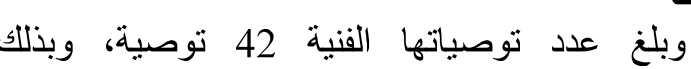

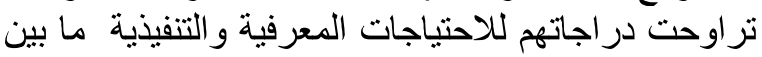

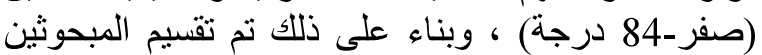
وفقا لمستوى احتياجهم المعرفي والتنفيذي لتلكي التونيم التوصيات

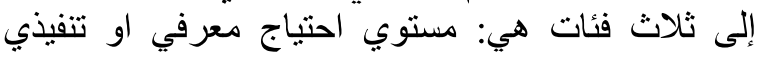

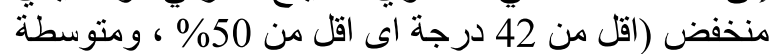

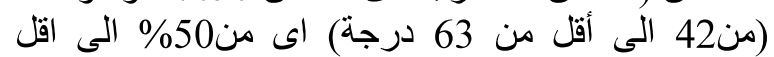

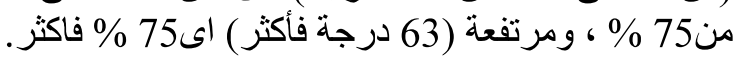

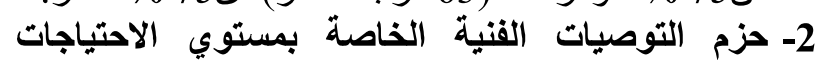

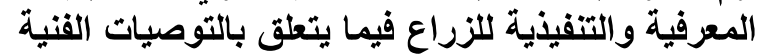

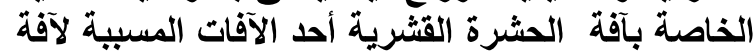

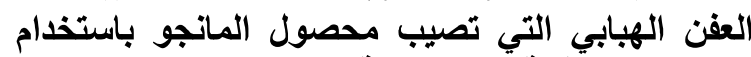
المبيدات بمحابفة الإسماعيلية:

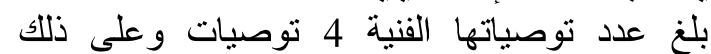
تراوحت درجاتهم لكل من الاحتياجات المعرفية والتنفيذي تلئي

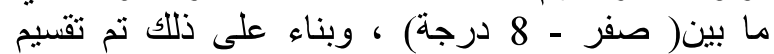
المبحوثين وفقا لمستوى احتياجهم المعرفي و التنفيذي لتلكي

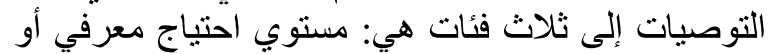

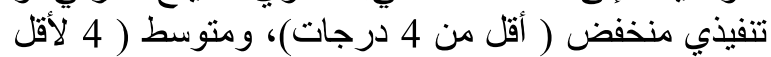
3ن 6 درجة)، ومرتفع ( 6 درنة درجة فأكثر).

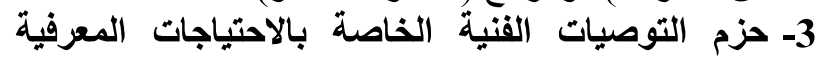
والتفيذية للزراع فيما يتعلق بالتوصيات الفنية الخاصة 


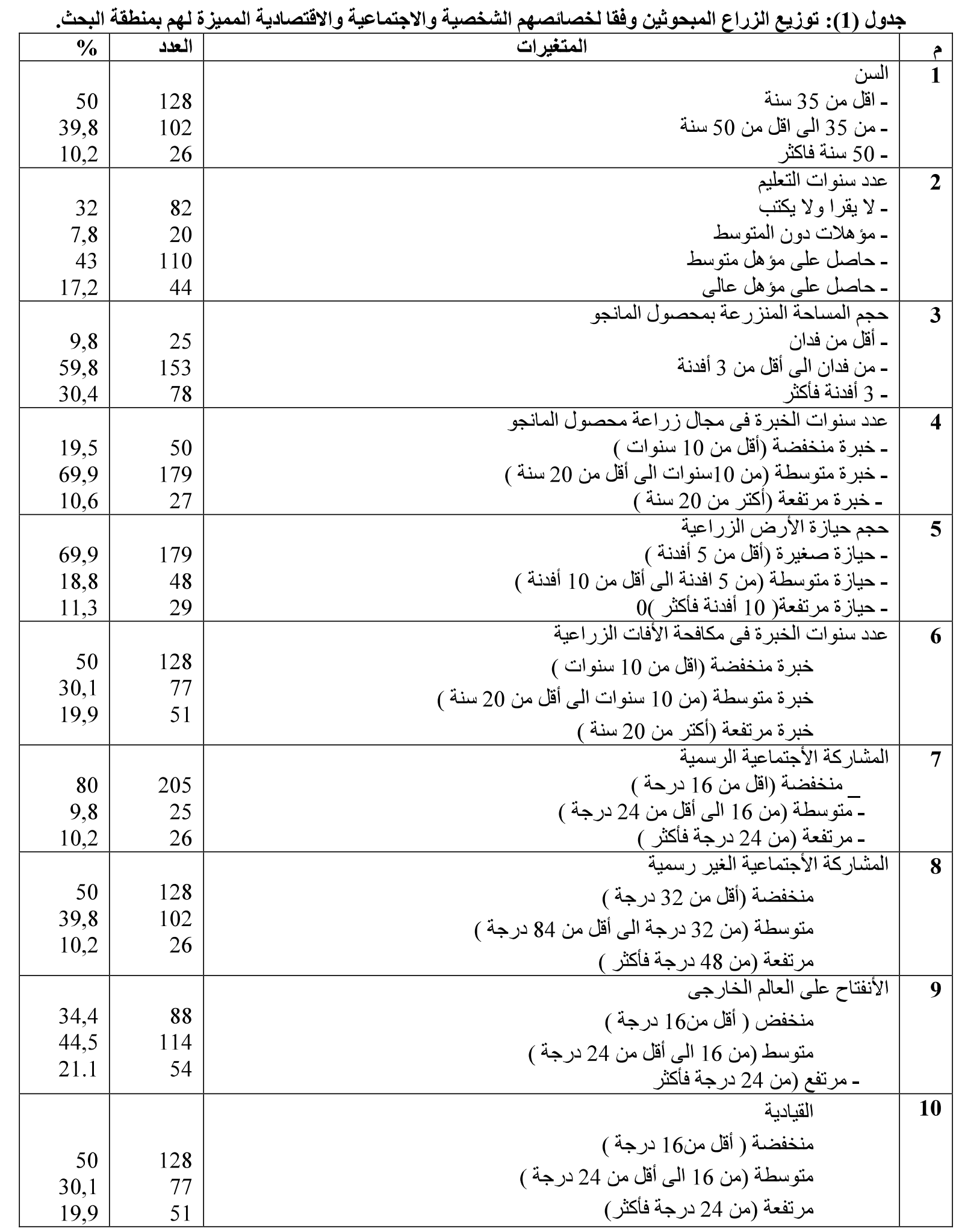

أفدنة، وما يقل عن ثلث المبحوثين حجم المساحة المنزر عة

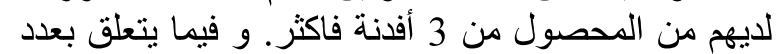

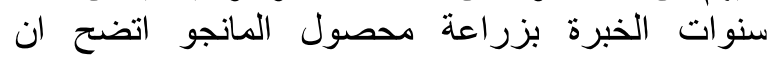

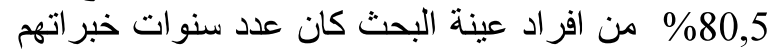

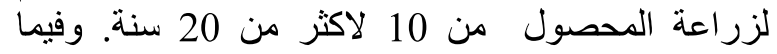

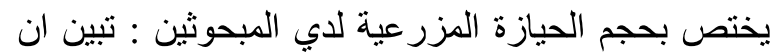

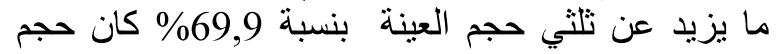

وفيما يتعلق بعدد سنوات التعليم للمبحوثين تبين ان ما يقرب من خمسى حجم العينة بنسبة 39,8 من فئة لائن لايقرأ و لايكتب ،ومؤهلات دون المتوسطة، وان حو اللى 60,2

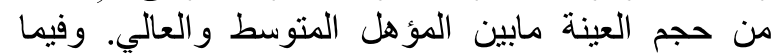

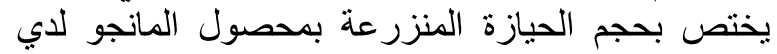

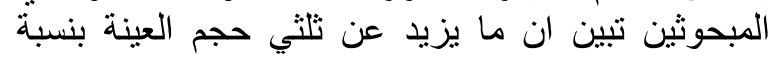
\%69,6 كان حجم الحيازة المنزرعة لديهم القل من 3 
جلول (3): توزيع المبحوثين وفتا لمستوي احتياجاتهم المعرفية

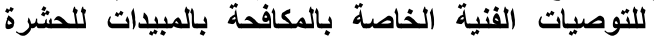

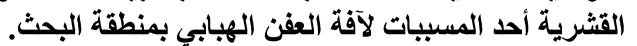

\begin{tabular}{|c|c|c|c|}
\hline النسبة & العدد & مستوى الاحتياج المعرفى & م \\
\hline 6,6 & 17 & منففض (أقل من 4 درجات ) & 1 \\
\hline 13 & 33 & متوسط (من 4 درجات لأقل من 6 درجات ) & 2 \\
\hline 80,4 & 207 & مرتفع (من 6 درحات فأكثر) & 3 \\
\hline 100 & 256 & الأجمالى & \\
\hline
\end{tabular}

ومتوسطا بنسبة 13\% من المبحوثين، بينما كان منخفض بنسبة 6,6\% من الزر اعن المبنو المبحوثين.

3- مستوي الاحتياجات المعرفية للزراع المئية المبحوثين فيما

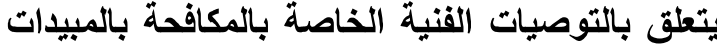
لكشرة المن أحد المسبيات لآفة العفن الهبابي بمنطقة بالكة البحث:

اتضح من الجدول (4) بان مستوى الأحتياج

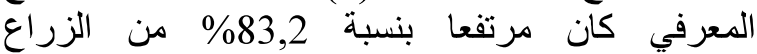

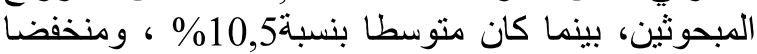
بنسبة 6,3\% من الزر اع ماع المبحوثين.

جدول (4): توزيع المبحوثين وفقا لمستوي احتياجاتهم المعرفية

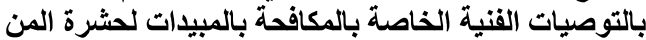

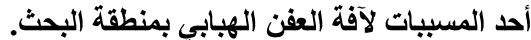

\begin{tabular}{|c|c|c|c|}
\hline$\%$ & العدد & مستوى الأحتياج المعرفى & p \\
\hline 6,3 & 16 & منخفض (أقل من 8 درجات ) & 1 \\
\hline 10,5 & 27 & متوسط (من 8 درجات لأقل من12 درجة ) & 2 \\
\hline 83,2 & 213 & مرتفع (من 12 درحة فأكثر ) & 3 \\
\hline 100 & 256 & المي & \\
\hline
\end{tabular}

4- مستوي الاحتياجات المعرفية للزراع المبحوثين فيما

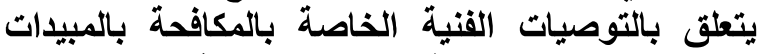
لمرض البياض الاقيقي أحد المسبيات لآفة العفن الهبابي بالي

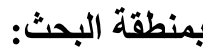

تشير النتائج الوارده بالجدول (5) بأن مستوى الاحتياج

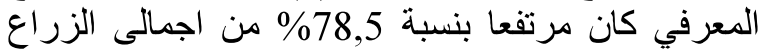

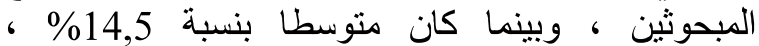
ومنخفضا بنسبة 7 \% من الزر اع المبحوثين.

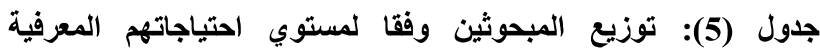

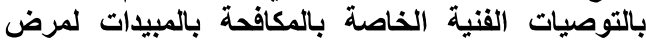
البياض الدقيقي أحد المسبيات لآفة العفن الهبابي بمنطقة

\begin{tabular}{|c|c|c|c|}
\hline & & \multicolumn{2}{|l|}{ البحث. } \\
\hline$\%$ & العدد & مستوى الاحتياج & 5 \\
\hline 7 & 18 & منخفض (أقل من 4 درجات) & 1 \\
\hline 14,5 & 37 & متوسط (من 4 درجات لأقل من 6 درجات) & 2 \\
\hline $\mathbf{7 8 , 5}$ & 201 & مرتفع (من 6 درجات فأكثر) & 3 \\
\hline 100 & 256 & 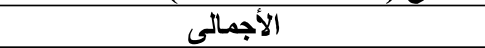 & \\
\hline
\end{tabular}

5- مستوي الاحتياج المعرفى للزراع المبحوثين فيما

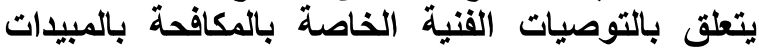
لمجموعة اخري من الأمراض الفطرية أحد المسبيات لآفة العفن الهبابي بمنطقة البحث:

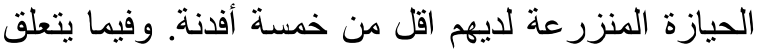

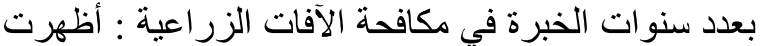

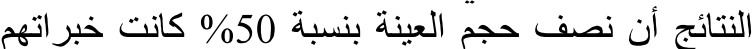

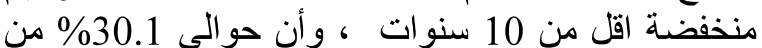

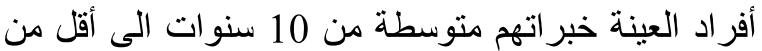
20 سنة ، وفى حين أن 19.9\% من أفر أفر اد العينة خبر اتهم

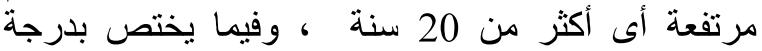

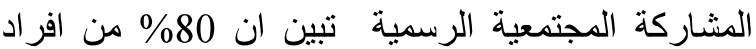

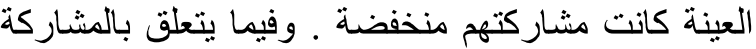
غير الرسمية: تبين ان نصف العينة (50\%) كان درجة

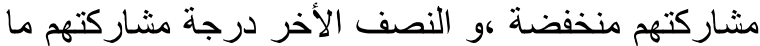
بين المتوسطة والمرتفعة. وفيما يتعلق بدرجة الانفي درجة الانتاح علي

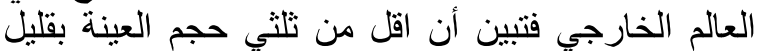

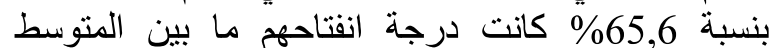

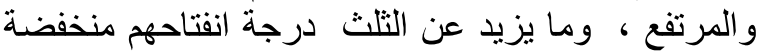

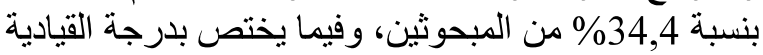
فقد تبين أن نصف حجم العينة بنسبة 50\% درجة درجة القيادة

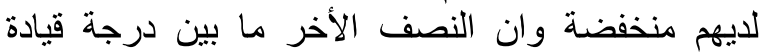
متوسطة ومرتفعة.

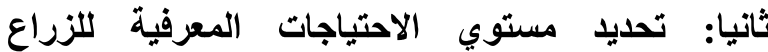

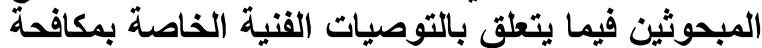
آقات العفن الهبابي بمحافظة الإسماعيلية من خلال النتائج

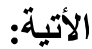

1- مستوي الاحتياجات المعرفية للزراع المبحوثين فيما

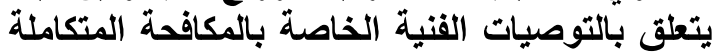
لآفة العفن الهبابي بمنطقة البحث:

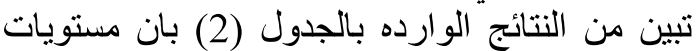

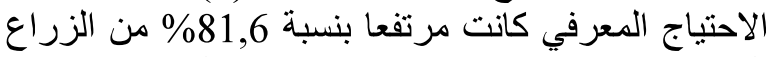

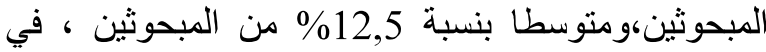

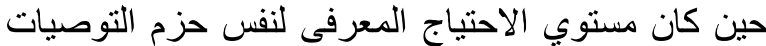

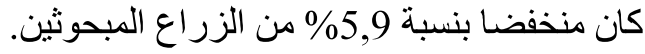

جدول (2): توزيع المبحوثين وفقا لمستوي احتياجاتهم المعرفية

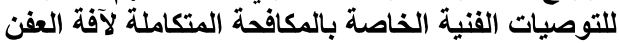

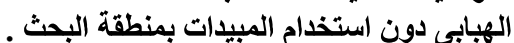

\begin{tabular}{|c|c|c|c|}
\hline$\%$ & العدد & مستوى الاحتياج المعرفى & e \\
\hline 5,9 & 15 & منخفض(أقل من 42 درجة ) & 1 \\
\hline 12,5 & 42 & متوسط (من 42 لأقل من 63 درجة ) & 2 \\
\hline 81,6 & 209 & مرتفع (من 63 درجة فأكثر ) & 3 \\
\hline 100 & 256 & الأجمالى & \\
\hline
\end{tabular}

2- مستوي الاحتياجات المعرفية للزراع المبحوثين فيما

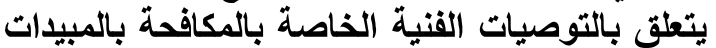
للحشرة القشرية أحد المسبيات لآفة العفن العندة الهبابي بمنطقة البحث: اتضح من النتائج بالجدول (3) بأن مستويات الاحتياج

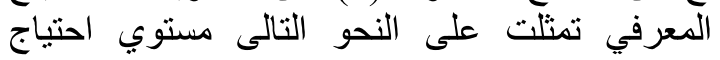

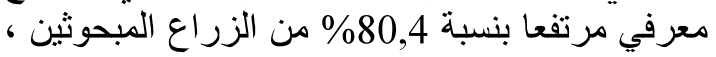


جدول (8): يوضح توزيع المبحوثين وفقا لمستوي احتياجاتهم التثفيذية

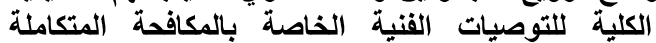

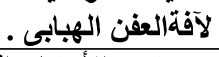

\begin{tabular}{|c|c|c|c|}
\hline$\%$ & 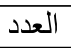 & مستوى الأحتباج التنفيذى & ? \\
\hline 3,9 & 10 & منخفض( أقل من 42 درجة ) & 1 \\
\hline 12,5 & 32 & متوسط( من 42 درجة لأقل من 63 درجة) & 2 \\
\hline 83,6 & 214 & مرتفع(من 63 درجة فاكثر ) & 3 \\
\hline 100 & 256 & 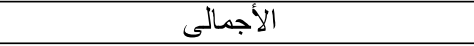 & \\
\hline
\end{tabular}

للحشرة القشرية أحد المسبيات لآفة العفن الهبابي بمنطقة البحث:

اتضح من النتائج بالجدول (9) بأن مستويات الاحتياج

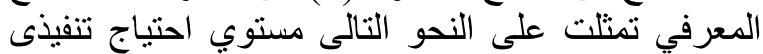
مرتفعا بنسبة 81,1\% من على الزراع المبحوثين ، ومتوسطا

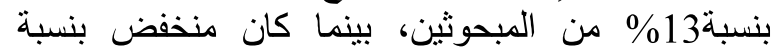
\% 5,9 من الزراع المبحوثين.

جدول (9): توزيع المبحوثين وفقا لمستوي احتياجاتهم التفيذية

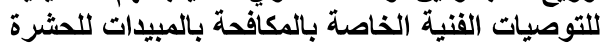
القشرية أحد المسبيات لآفة العفن الهباهية بالمبيدى بمنطقة

\begin{tabular}{|c|c|c|c|}
\hline \multicolumn{4}{|c|}{ البحث . } \\
\hline$\%$ & العدد & مستوى الأحتياج التنفيذى & م \\
\hline 5,9 & 15 & منخفض( أقل من 4 درجات ) & 1 \\
\hline 13 & 33 & متوسط( من 4 درجات لأقل من 6 درجة ) & 2 \\
\hline 81,1 & 208 & مرتفع(من 6 درجات فاكثر ) & 3 \\
\hline 100 & 256 & الأجمالى & \\
\hline
\end{tabular}

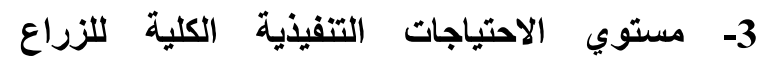

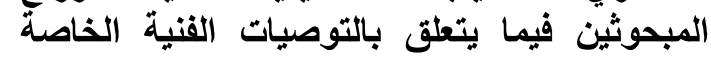

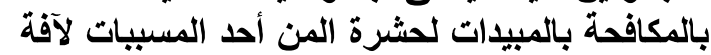

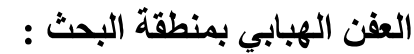

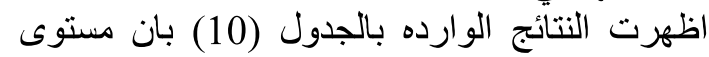

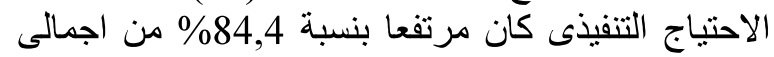

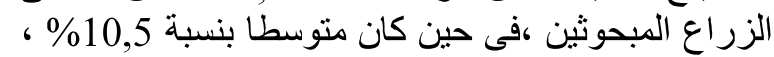
ومنخفضا بنسبة 4,7 \% من الزر اع المبحوثين.

جدول (10): توزيع المبحوثين وفقا لمستوي احتياجاتهم التنفيذية

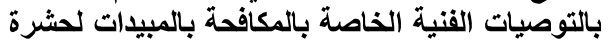

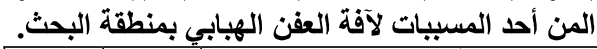

\begin{tabular}{|c|c|c|c|}
\hline$\%$ & العدد & مستوى الأحتياج التنفيذى & م \\
\hline 4,7 & 12 & منخفض( أقل من 8 درجات ) & 1 \\
\hline 10,5 & 27 & درجة) متط من 8 درجات لأقل من 12 & 2 \\
\hline 84,4 & 217 & مرتفع(من 12 درجات فاكثر ) & 3 \\
\hline 100 & 256 & الأجمالى & \\
\hline
\end{tabular}

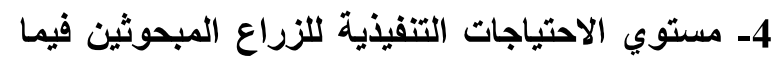

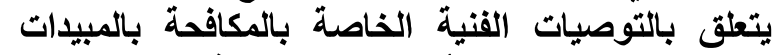

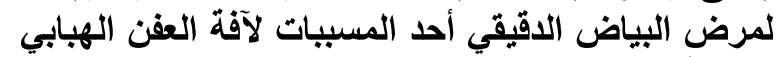
بمنطقة البحث: الباض

تشير النتائج الوارده بالجدول (11) بأن مستوى التوى

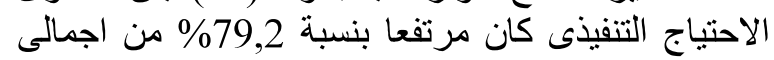

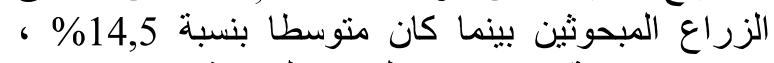
ومنخفضا بنسبة 6,3 \% من الزبن كان لزوراع المبحوثين.
أظهرت من النتائج الوارده بالجدول (6) ان مستويات

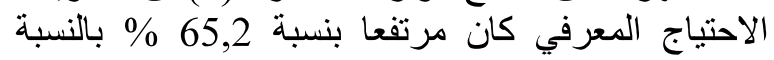

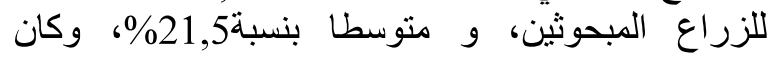
منخفضا بنسبة 13,3 \% من اجمالى المبحوثين.

جدول(6) توزيع المبحوثين وفقا لمستوي احتياجاتهم المعرفية

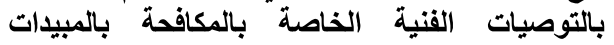

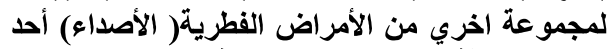

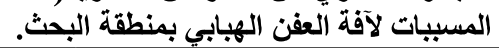

\begin{tabular}{|c|c|c|c|}
\hline$\%$ & 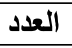 & مستوى الأحتياج المعرفى & ? \\
\hline 13,3 & 34 & منخفض( أقل من 8 درجات ) & 1 \\
\hline 21,5 & 55 & متوسط(من 8 درجات لأقل من 12 درجة ) & 2 \\
\hline 65,2 & 167 & مرتفع(من 12 درجة فأكثر ) & 3 \\
\hline 100 & 256 & 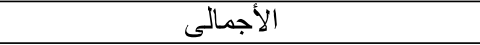 & \\
\hline
\end{tabular}

6- مستوي الأحتياجات المعرفية الكلية للزراع المبحوثين

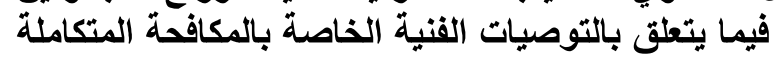

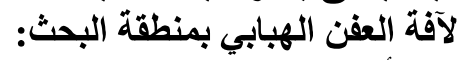

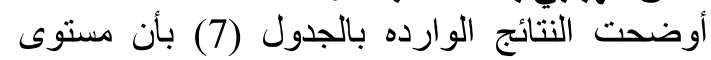

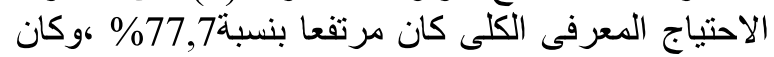

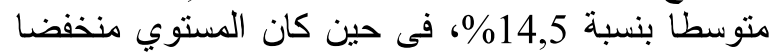

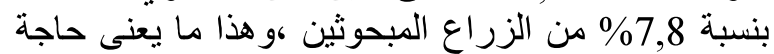

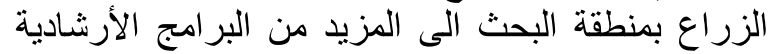

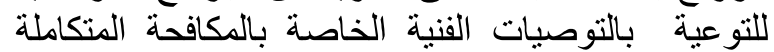

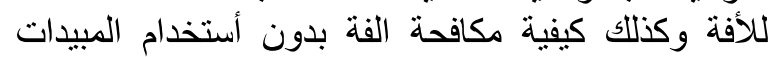

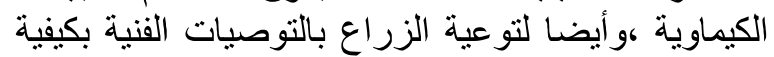

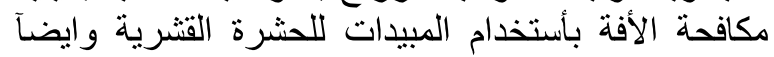

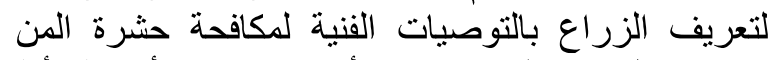
ومرض البياض الدقيقى وهما أحد مسبيات الأصسابة بأفة لئة

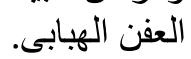

جدول (7): توزيع المبحوثين وفقا لمستوي احتياجاتهم المعرفية العامة للتوصيات الفنية الخاصة بالمكافحة المتكاملة لآفة العفن

\begin{tabular}{|c|c|c|c|}
\hline & & \\
\hline$\%$ & العدد & مستوى الأحتياج المعرفى & \\
\hline 7,8 & 20 & |منغفض( أقل من 66 درجة ) & 1 \\
\hline 14,5 & 37 & هتوسط( من 66 درجة لأقل من 99 درجة ) & 2 \\
\hline 77,7 & 199 & مرتفع(من 99 درجة فاكثر ) & 3 \\
\hline 100 & 256 & 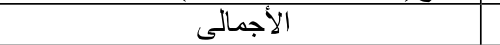 & \\
\hline
\end{tabular}

ثالثا: تحديد مستوي الاحتياجات الإرشادية التتفيذية للزراع المبحوثين فيما يتعلق بالتوصيات الإثياتية الفئية

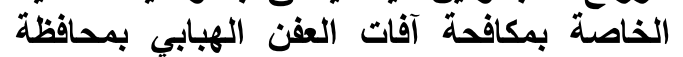
الإسماعيلية من خلال النتائج الأتية:

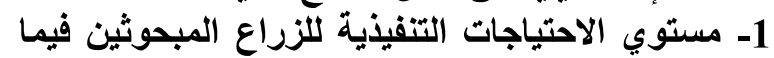

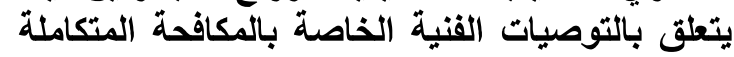

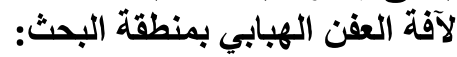

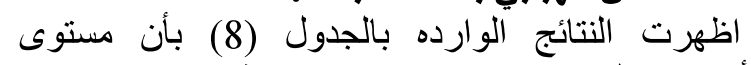

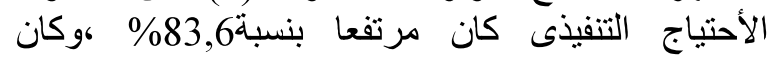

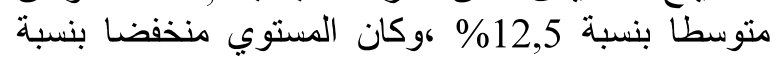

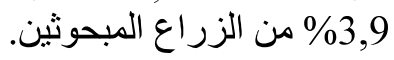

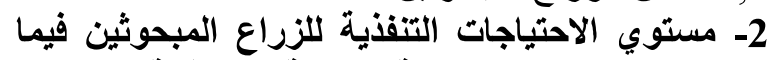
يتعلق بالتوصيات القنية الخاصة بالمكافحة بالمبيدات 


\section{الهبابي بمحافظة الإسماعيلية، وبين كل من المتغيرات المستقلة المدروسة.}

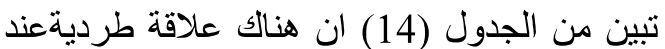
كستوي معنوي (0,01) بين درجة الأحتياج المعرفي وبين العين

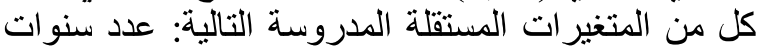

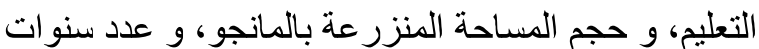

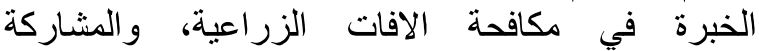
الاجتماعية غير الرسمية، وبينما كان ذات الزات العلاقة طردية التراتية

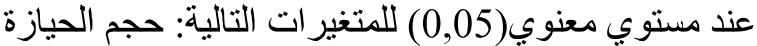

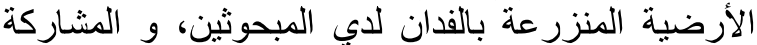

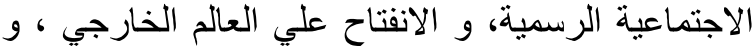

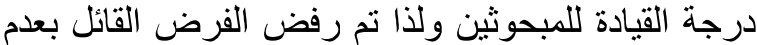

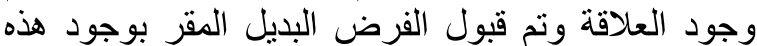

العلاقة لكافة المتغير ات السابق ذاتئ ذكر ها.

خامسا : تحديد العلاقة بين كل من درجة دالئة الاحتياجات

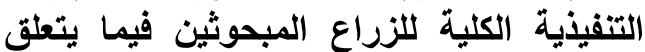

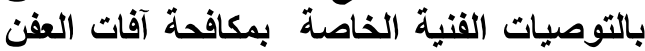

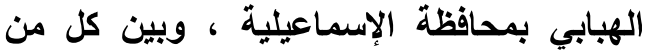
المتغيرات المستقلة المدروسة. اتضح من نتائج الجدول (15) وجود علئة الماقة ارتباطية طردية عند مستوي معنوي (0,01) بين كل من الجنائ درجية

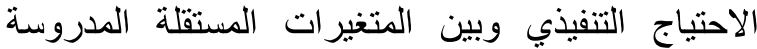

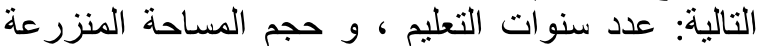

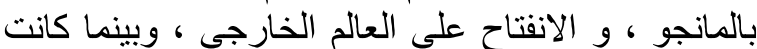

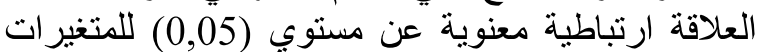

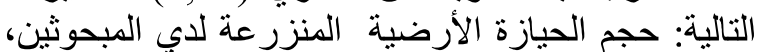

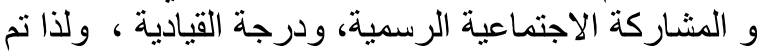

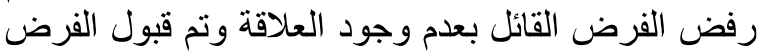
البديل المقر بوجود هذه العلاقة لكافة المتغيرات الستانيق السابق

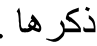

سادسا: التعرف علي أهم المصادر التي يستقي منها الزراع

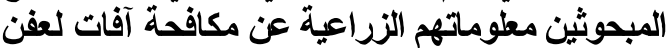
الهبابع بمحافظة الإسماعيلية:

اتضح من الجدول (16): أهم المصادر التي يستقي منهاعيا

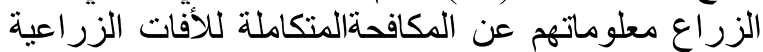

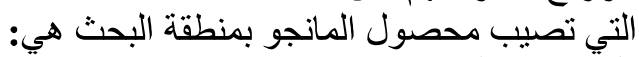

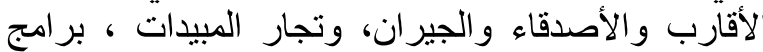

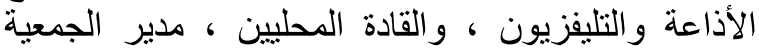

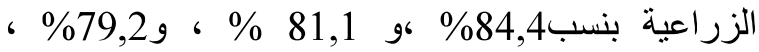

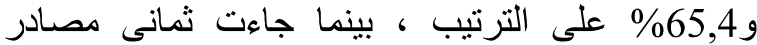
آخرى بعد ذلك ثراوحت نسبتها ما بين 46,9\% التي $\% 6,3$

سابعا : التعرف علي أهم الخدمات الإرشادية الزراعية المقدمة للزراع من قبل الجهاز الارشادي الزئرائ الزراعي

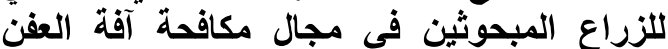
الهبابي بمحافظة الاسماعيلية: اتضح من نتائج الجدول (17) أن أهم الخداعية الخدمات الإرشادية المقدمة من الإرشاد الزر اعي من وجهة نظر هم التمات
جدول (11): توزيع المبحوثين وفقا لمستوي احتياجاتهم التنفيذية

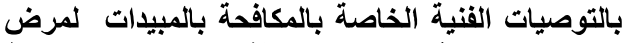
البياض الاقيقى أحد المسبيات لآفة العفن الهبابي بمنطقة

\begin{tabular}{|c|c|c|c|}
\hline & & حت. & \\
\hline$\%$ & العدد & مستوى الأحتياج التنفيذى & 5 \\
\hline 6,3 & 16 & منخفض( أقل من4 درجات ) & 1 \\
\hline 14,5 & 37 & متوسط( من4 درجات لأقل من 6 درجة ) & 2 \\
\hline 79,2 & 203 & مرتقع(من 6 درجات فاكثر ) & 3 \\
\hline 100 & 256 & 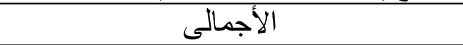 & \\
\hline
\end{tabular}

5- مستوي الاحتياج التنفيذى للزراع المبحوثين فيما

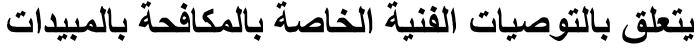
لمجموعة اخري من الأمراض الفطرية الحئ الحد المسبيات بالمبات لآفة العفن الهبابي بمنطقة البحث:

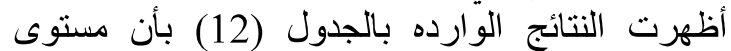

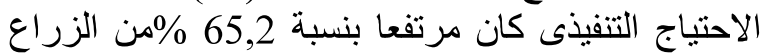

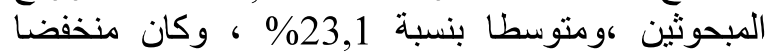
بنسبة 11,7\% من اجمالى المبحوثين.

جدول (12): توزيع المبحوثين وفقا لمستوي احتياجاتهم التنفيذية

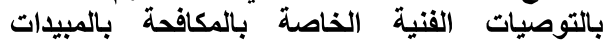

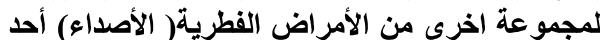
المسبيات لآفة العفن الهبابي بمنطقة البحث.

\begin{tabular}{|c|c|c|c|}
\hline$\%$ & العدد & مستوى الاحتياج التنفيذى & م \\
\hline 11,7 & 30 & منذفض (أقل من 8درجات ) & 1 \\
\hline 23,1 & 59 & درجات (من 8 درجات لأقل من 12 & 2 \\
\hline 65,2 & 167 & مرتفع (من 12 درجة فأكثر ) & 3 \\
\hline 100 & 256 & الأجمالى & \\
\hline
\end{tabular}

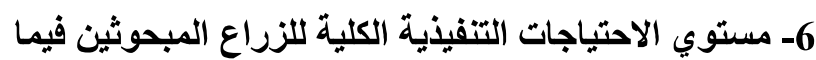

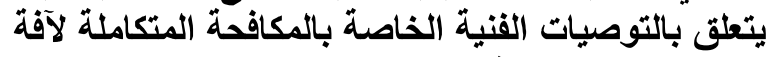
العفن الهبابي بمنطقة البحث:

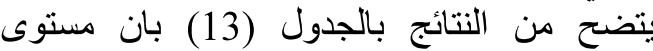

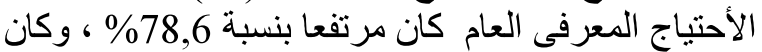

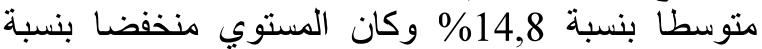

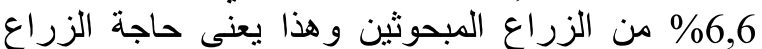

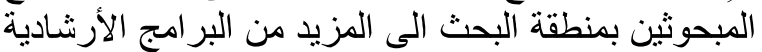

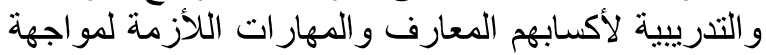

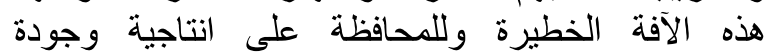
محصول المانجو بمحافظة الأسماعيلية منطقة البحث.

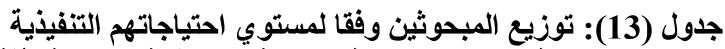

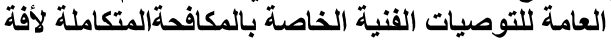

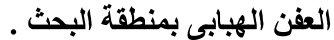

\begin{tabular}{|c|c|c|c|}
\hline$\%$ & العدد & مستوى الاحتياج التنفيذى & \\
\hline 6,6 & 17 & منخفض (أقل من 66درجة ) & 1 \\
\hline 14,8 & 38 & متوسط (من 66 درجات لأقل من 99 درجة ) & 2 \\
\hline 78,6 & 201 & مرتفع (من 99 درجة فأكثر ) & 3 \\
\hline 100 & 256 & I1) & \\
\hline
\end{tabular}

رابعا: تحديد طبيعة العلاقة بين كل من درجة الاحتياجات

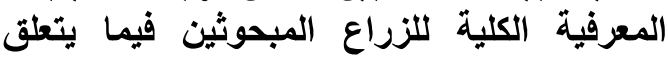
بالتوصيات القنية الخاصة بمكافحة آلقات العفن العنات 
جدول (14): طبيعة العلاقة بين كل من درجة الاحتياجات المعرفية الكلية للزراع المبحوثين فيما يتعلق بالتوصيات الفنية الخاصة بمكافحة

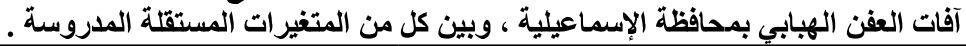

\begin{tabular}{|c|c|c|}
\hline معامل الأرتباط بين الأحتياج المعرفى والمتغيرات المستقلة المدروسة & المتغيرات المستقلة & p \\
\hline 0,011 & 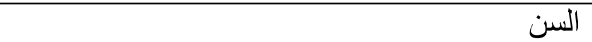 & 1 \\
\hline$* * 0,512$ & عدد سنوات التعليم & 2 \\
\hline$* * 0,616$ & حجم المساحة المنزر عة بالمانجو & 3 \\
\hline$* 0,016$ & عدد سنو ات الخبرة فى مجال زر اعة محصول المانجو & 4 \\
\hline$* 0,196$ & حجم حيازة الأرض المنزرعة & 5 \\
\hline$* * 0,327$ & عدد سنوات الخبرة فى مكافحة الأفات الزر اعية & 6 \\
\hline$* 0,161$ & المشاركة الأجتماعية الرسمية & 7 \\
\hline$* * 0,245$ & المشاركة الأجتماعية غير الرسمية & 8 \\
\hline$* 0,185$ & الأنتاح على العالم الخارجى & 9 \\
\hline $0 * 0,194$ & درجة القيادية & 10 \\
\hline
\end{tabular}

جدول (15): طبيعة العلاقة بين كل من درجة الاحتياجات التفيذية الكلية للزراع المبحوثين فيما يتعلق بالتوصيات الفنية الخاصة بمكافحة

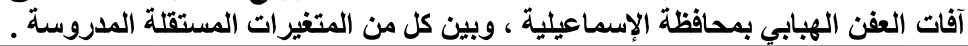

\begin{tabular}{|c|c|c|}
\hline معامل الأرتباط بين الأحتياج التنفيذى والمتغيرات & المتغيرات المستقلة & م \\
\hline 0,1 & 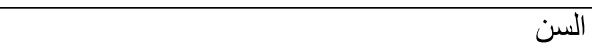 & 1 \\
\hline$* * 0,281$ & عدد سنوات التعليم & 2 \\
\hline$* * 0,522$ & حجم المساحة المنزر عة بالمانجو & 3 \\
\hline 0,051 & عدد سنوات الخبرة فى مجال زر اعة محصول المانجو & 4 \\
\hline$* 0,194$ & حجم حيازة الأرض المنزرعة & 5 \\
\hline 0,017 & عدد سنو ات الخبرة فى مكافحة الأفات الزر اعية & 6 \\
\hline$* 0,160$ & المشاركة الأجتماعية الرسمية & 7 \\
\hline 0,016 & المشاركة الأجتماعية غير الرسمية & 8 \\
\hline$* * 0,184$ & الأنفتاح على العالم الخارجى & 9 \\
\hline$* 0,192$ & درجة القيادية & 10 \\
\hline
\end{tabular}

05 معنوية عند مسنوى**

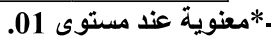

جدول (16): توزيع الزراع المبحوثين تنازليا وفقا لذكرهم لأهم المصادر الزراعية التي يستقون منها معلوماتهم عن آفة العفن الهبابي

\begin{tabular}{|c|c|c|c|}
\hline & & \multicolumn{2}{|l|}{ وطرق مكافحتها. } \\
\hline$\%$ & عدد & مصادر المعلومات & م \\
\hline 84,4 & 217 & الأقارب والأصدقاء و الجيران & 1 \\
\hline 81,1 & 208 & تجار المبيدات & 2 \\
\hline 79,2 & 203 & بر امج الإذاعة و التليفزيون & 3 \\
\hline 65,3 & 167 & القادة المحليين & 4 \\
\hline 46,9 & 120 & مدير الجمعية & 5 \\
\hline 40,2 & 103 & المرشد الزر اعي & 6 \\
\hline 39,5 & 101 & مشرف الحوض & 7 \\
\hline 33.2 & 85 & مدير المركز الإرشادي & 8 \\
\hline 31.3 & 80 & رئيس قسم الإرشاد بالمركز & 9 \\
\hline 28,9 & 74 & رئبس قسم المكافحة بالمركز الإرشادي & 10 \\
\hline 24,6 & 63 & رئيس قسم المكافحة بالإدارة الزر اعية & 11 \\
\hline 6,3 & 16 & الباحثين بالمر اكز البحثية و الجامعات & 12 \\
\hline
\end{tabular}


جدول (17): توزيع الزراع المبحوثين وفقا ذكرهم لأهم الخدمات الإرشادية المقدمة من الإرشاد الزراعي من وجهة نظرهم للتعامل

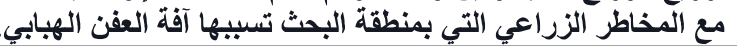

\begin{tabular}{|c|c|c|c|}
\hline$\%$ & عدد & الخذمات الإرشادية المقدمة في مجال مرض ومكافحة آفة العفن الهبابي & $p$ \\
\hline 40,2 & 103 & زيارة المرشد للحقل الزر اعي لتقديم النصح بسبل التعامل مع آفة العفن الهبابي & 1 \\
\hline 39,5 & 101 & زيارة المرشد للمنزل الزر اعي لنقديم النصح بسبل التعامل مع الآفة & 2 \\
\hline 31,3 & 80 & زيارة المز ارع للمرشد بمكتبه لتلقي الإرشادات للتعامل مع الآفة & 3 \\
\hline 28,9 & 74 & الندوات الإرشادية الزر اعية في مجال التخطيط لمو اجهة الآفة & 4 \\
\hline 14,5 & 37 & الاجتماعات الإرشادية الزر اعية للتوعية بكيفية مواجهة الآفة & 5 \\
\hline 14,5 & 37 & الحقول الإرشادية للتوضيح العملى بكيفية مكافحة الآفة & 6 \\
\hline 10,5 & 27 & أيام حقل لشر ح سبل مواجهة الآفة & 7 \\
\hline 10,5 & 27 & التو عية من خلال البرامج الإذاعية و التليفزيونية لمكافحة الآفة & 8 \\
\hline 6,3 & 16 & توزيع المطبو عات و النشر ات لمواجهة المخاطر الزراعية في حال الإصابة بالآفة & 9 \\
\hline 5,9 & 15 & زيار ات الباحثين و أساتذة الجامعات لتقديم التوصيات الحديثة & 10 \\
\hline 4,7 & 12 & التدريب علي مواجهة المخاطر بأساليب علمية وعملية & 11 \\
\hline 4,7 & 12 & زيارات الزراع لمر اكز إدارات الأزمات الموجود بالأقليم و التي تسبيها الآفات الزر اعية & 12 \\
\hline
\end{tabular}

الهنيدى، احمد حسين، وفياض، يحي حسين (2004).

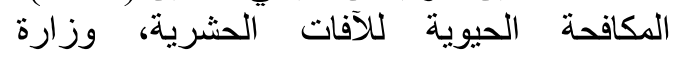

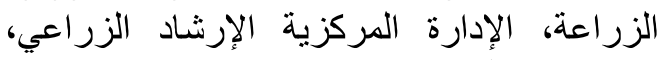

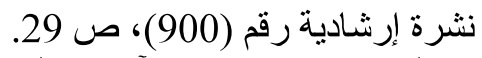

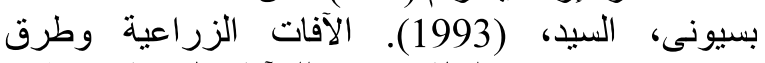

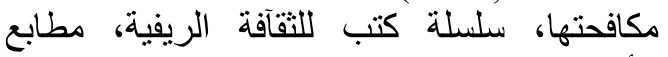

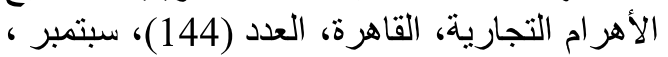

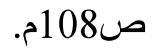

دبور، علي وشاكر حماد،(1982). الآفات الحشرية

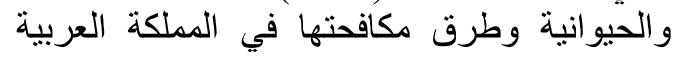

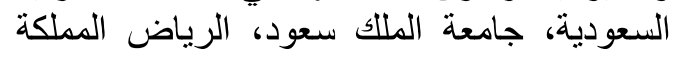

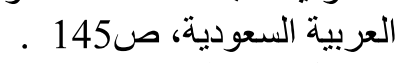

رويثدي، خالد، محملجي، محمد زهير، العير، (1990) ـ بيئة

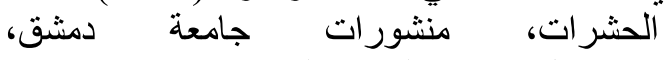

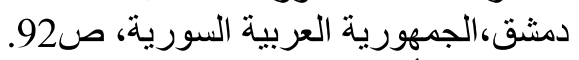
رويثدي، خالد وأبو دلال، نذير إلئهة إسماعيل، (2011).

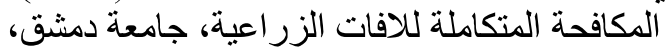

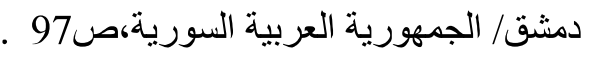

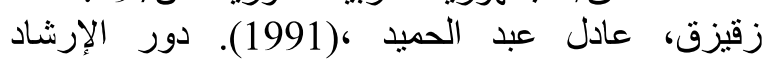
الزراعى فى تقليل فاقد محصول الدول الطماطم بقرية الإنية

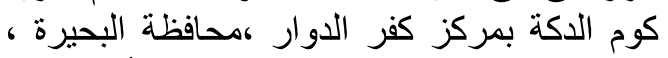
رسالة ماجستير ،كلية الزر اعة ،جرئ ،جامعة الأسكندرية، البحير،

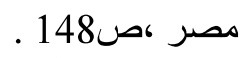
سويلم، محمد نسيم على، (1978). الإحتياجات الأرشادية

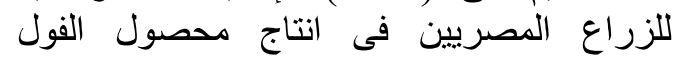

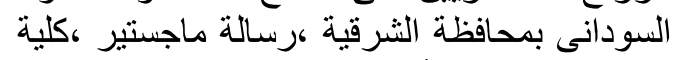

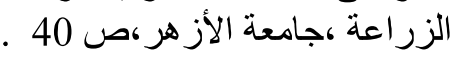

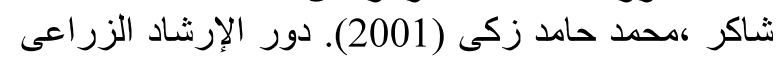

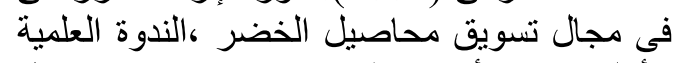
الأولى عن الأرشاد الزراعى تهيق وتسويق محاصيل

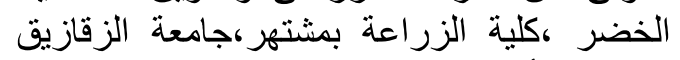

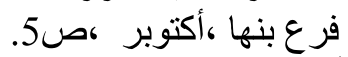
عليوة ،أحمد جلال عويس، (1983) لكوبر الإحتياجات الأرشادية لزراع الخضر بمحافظة الفيوم ، كليـــــة الإنيات
للتعامل مع المخاطر التي تسببها آفة العفن الهبابي بمنطقة

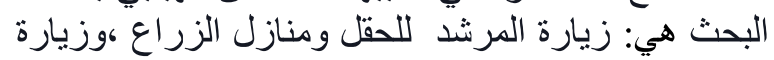

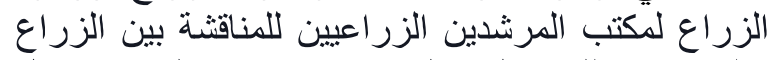

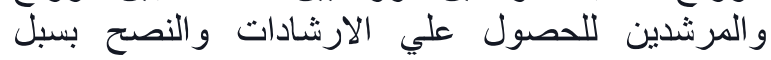

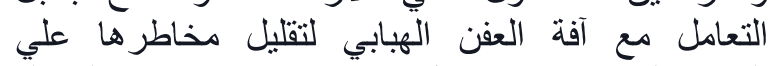

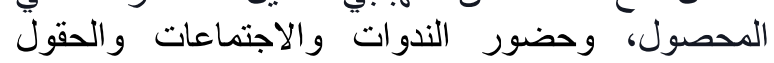

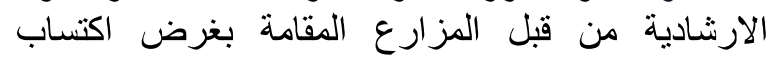

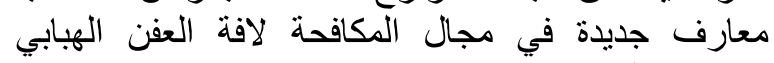

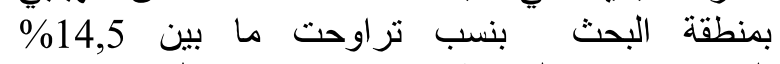

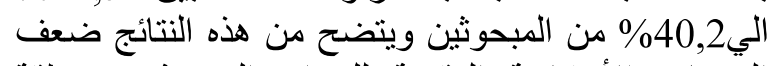
الخدمات الأرشادية المقدمة للزراع المبحوثين هذهن بمنطقة البحث . - (الخمات

\section{6. - - المراجع}

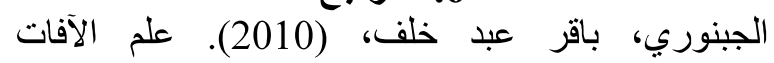
الزير اعية، كلية الزر اعة، جامعة الموصل، العرل، العرات،

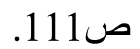

الزميتى، محمد السعيد صلالح، (1997). تطبيقات المكافحة

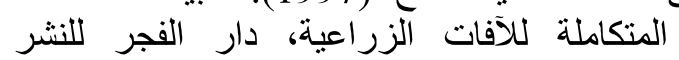

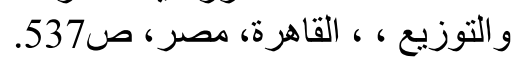

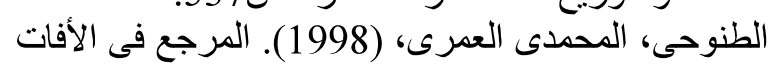

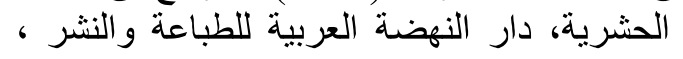

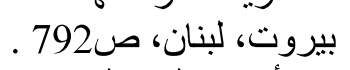

المقوشى ، أحمد على سليمان(2009) صلئل (رسالة ماجستير)

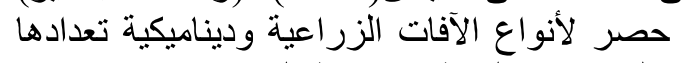

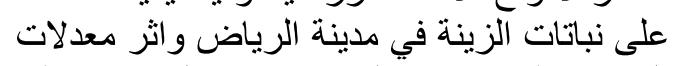

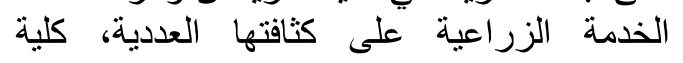
الزراعة، جامعة الملك سعودة، الزعلة المملكة العربية

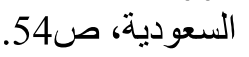

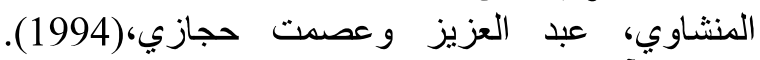
الآفات الحشرية والحيو وعيد وانية وعلاقتها بالنبات

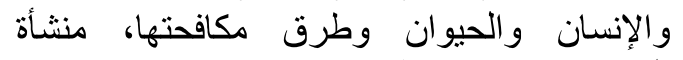
المعارف بالإسكندرية،مصر وطرن ، ص29. 


\section{REFERENCES}

Agunga R. A. (1995). What Ohio Extension Agents Say About Sustainable Agriculture , J. Sust.. Agric. ,513.

Alahmadi A. Z and Salem M. M .(1999). Entomofauna of Saudi Arabia, General Survey of Insects Reported in the Kingdom of Saudi Arabia. King Saud University Press. Part $240 ، 1$ pp.10

Blackman, R. L. and Eastop F. (1984). Aphids on the World's Crops: An Identification and Information Guide. John Wiley and Sons, London, UK. 466 pp162.

Blackman R. L. and Eastop V. F. (1984). Aphids on the World's Crops, An Identification Guide. John Wiley \& Sons, New York. 466,pp128.

Guldemond J. D. , Thgges W. T. and Vrijer W. E. (1994). Host races of Aphis gossypii (Homoptera: Aphididae) on cucumber and chrysanthemum. Environ. Entomol, 23: 1235-1240.

Kerejcie R. V. and Morgan D. W.(1970). "Determining Sample Size For Research Activities". Educational and Psychological Measurement, pp604.

Moursi K. S., Donia A. A., Mesbah H. A. and Haroum N. S.(1985). Comparative studies of Aphis gossypii Glov. On different host plants Ann. Agric. Soc. Moshohor 23,pp 122.

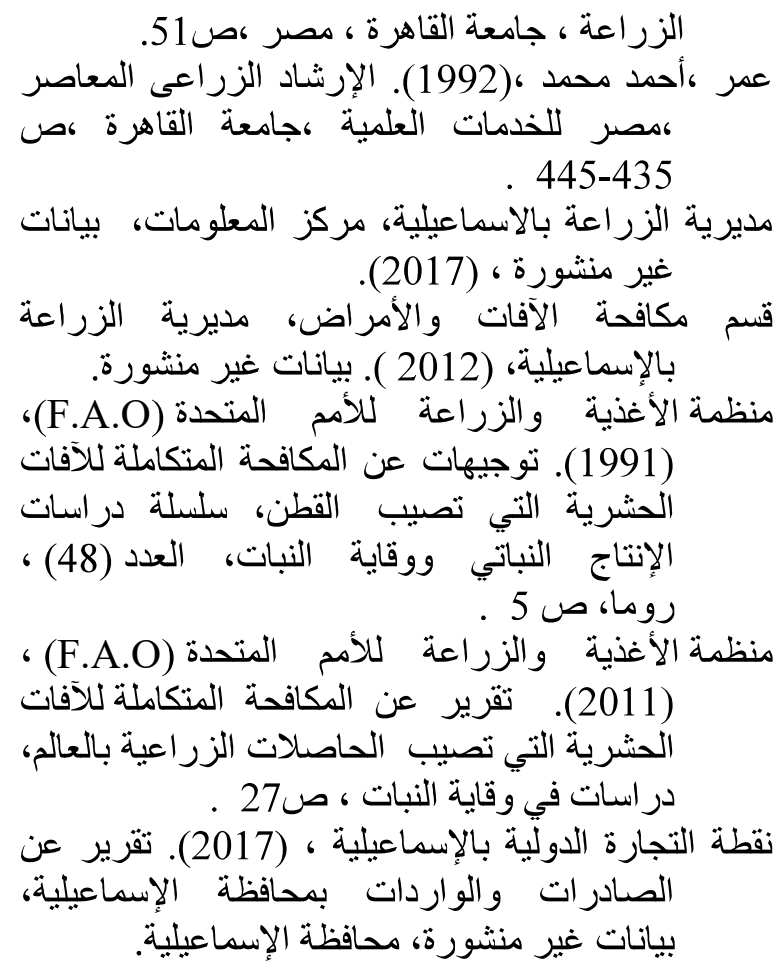

